\title{
Brucella abortus Induces the Secretion of Proinflammatory Mediators from Glial Cells Leading to Astrocyte Apoptosis
}

\author{
Clara García Samartino, ${ }^{\star \dagger}$ M. Victoria Delpino, ${ }^{\dagger}$ \\ Clara Pott Godoy, ${ }^{\ddagger}$ María Silvia Di Genaro, ${ }^{\S}$ \\ Karina A. Pasquevich, ${ }^{* \dagger}$ Astrid Zwerdling, ${ }^{* \dagger}$ \\ Paula Barrionuevo, ${ }^{\star \dagger}$ Patricia Mathieu, ${ }^{\ddagger}$ \\ Juliana Cassataro, ${ }^{* \dagger}$ Fernando Pitossi, ${ }^{\ddagger}$ \\ and Guillermo H. Giambartolomei ${ }^{\star \dagger}$ \\ From the Instituto de Estudios de la Inmunidad Humoral \\ (CONICET),* Facultad de Farmacia y Bioquímica, Universidad \\ de Buenos Aires, Buenos Aires; the Laboratorio de \\ Inmunogenética, ${ }^{\dagger}$ Hospital de Clinicas "José de San Martín," \\ Facultad de Medicina, Universidad de Buenos Aires, Buenos \\ Aires; the Fundacion Instituto Leloir, ${ }^{\ddagger}$ Buenos Aires; and the \\ Instituto de Investigaciones Biológicas_San Luis (CONICET), ${ }^{\S}$ \\ Facultad de Química, Bioquímica y Farmacia, Universidad \\ Nacional de San Luis, San Luis, Argentina
}

Central nervous system (CNS) invasion by bacteria of the genus Brucella results in an inflammatory disorder called neurobrucellosis. In this study we present in vivo and in vitro evidence that $B$. abortus and its lipoproteins activate the innate immunity of the CNS, eliciting an inflammatory response that leads to astrogliosis, a characteristic feature of neurobrucellosis. Intracranial injection of heat-killed $B$. abortus (HKBA) or outer membrane protein 19 (Omp19), a B. abortus lipoprotein model, induced astrogliosis in mouse striatum. Moreover, infection of astrocytes and microglia with $B$. abortus induced the secretion of interleukin (IL)-6, IL-1 $\beta$, tumor necrosis factor (TNF)- $\alpha$, macrophage chemoattractant protein-1, and KC (CXCL1). HKBA also induced these inflammatory mediators, suggesting the involvement of a structural component of the bacterium. Accordingly, Omp19 induced the same cytokine and chemokine secretion pattern. $B$. abortus infection induced astrocyte, but not microglia, apoptosis. Indeed, HKBA and Omp19 elicited not only astrocyte apoptosis but also proliferation, two features observed during astrogliosis. Apoptosis induced by HKBA and L-Omp19 was completely suppressed in cells of TNF receptor p55 $5^{-/-}$mice or when the general caspase inhibitor
Z-VAD-FMK was added to cultures. Hence, TNF- $\alpha$ signaling via TNF receptor (TNFR) 1 through the coupling of caspases determines apoptosis. Our results provide proof of the principle that Brucella lipoproteins could be key virulence factors in neurobrucellosis and that astrogliosis might contribute to neurobrucellosis pathogenesis. (Am J Pathol 2010, 176:1323-1338; DOI: 10.2353/ajpath.2010.090503)

Human brucellosis is a zoonotic infection caused by four Brucella species: B. melitensis, B. suis, B. abortus, and B. canis. Brucellosis is chiefly an inflammatory disease. Inflammation is present both in the acute and chronic phases of the disease and in virtually all of the organs affected. Clinical signs of such inflammation are undulant fever, endocarditis, arthritis, osteomyelitis, meningitis, pleocytosis, lymphocytic, and monocytic infiltration of the joints, orchitis, nephritis, hepatic granuloma, etc. ${ }^{1}$

The most likely molecular basis of the inflammatory effectiveness of $B$. abortus has recently become apparent. Although B. abortus, a Gram-negative bacterium, possesses lipopolysaccharide (LPS), the generic endotoxin of Gram-negative organisms, it may derive its inflammatory capacity from lipoproteins. At variance with the LPS from the Enterobacteriaceae, Brucella LPS has thus far been found to be virtually devoid of proinflammatory activity. ${ }^{2}$ Moreover, we have recently shown that the production of proinflammatory cytokines by monocytes/macrophages and dendritic cells is induced by

Supported by grants PICT 05-14305 and 1335 (2006) from the Agencia Nacional de Promoción Científica y Tecnológica (ANPCYT-Argentina), PIP 5213 from CONICET (Argentina), B819 from the Universidad de Buenos Aires (Argentina), and 17-2004 from Centro Argentino Brasileño de Biotecnología (CABBIO). C.G.S., C.P.G., A.Z., and K.A.P. are recipients of a fellowship from CONICET (Argentina). M.V.D., P.B., J.C., S.M.D., P.M., F.P., and G.H.G. are members of the Research Career of CONICET

Accepted for publication November 12, 2009.

Address reprint requests to Dr. Guillermo H. Giambartolomei, Instituto de Estudios de la Inmunidad Humoral (IDEHU), Facultad de Farmacia y Bioquímica, Universidad de Buenos Aires. Junín $9564^{\text {to }}$ Piso. (1113) Buenos Aires, Argentina. E-mail: ggiambart@ffyb.uba.ar. 
Brucella lipoproteins rather than LPS. ${ }^{3-5}$ Bacterial lipoproteins are powerful inflammatory molecules that are capable, for example, of inducing inflammatory cytokines such as interleukin (IL)-6, IL-1 $\beta$, and tumor necrosis factor (TNF)- $\alpha$. The genome of $B$. abortus contains no less than 80 genes encoding putative lipoproteins. ${ }^{6}$ Because it is the lipoprotein lipid moiety, shared by all bacterial lipoproteins, which endows this type of molecule with inflammatory properties, ${ }^{7}$ the inflammatory potential of Brucella must be considerable.

As with other manifestations of brucellosis, neurobrucellosis, which is perhaps the most morbid form of the disease, also presents inflammatory signs and symptoms. It affects mostly the central nervous system (CNS), and it has ominous prognosis. ${ }^{8}$ CNS neurobrucellosis may manifest as meningitis, encephalitis, meningoencephalitis, meningovascular disease, brain abscesses, demyelinating syndromes, and myelitis. Encephalitis and myelitis are both caused by the direct presence of the bacterium in the cerebral tissue and the spinal cord. ${ }^{9}$ Other signs of inflammation of the CNS that are associated with neurobrucellosis are reactive microgliosis and astrogliosis. ${ }^{10,11}$ Although the brain is rarely biopsied in brucellosis cases, and relatively few microscopic descriptions of CNS pathology have been published, these descriptions consistently reported a diffuse involvement of the white matter together with astrogliosis and reactive microgliosis. ${ }^{10,11}$

The clinical and imaging aspects of neurobrucellosis have been widely described, yet the pathogenic mechanisms involved in damage to the CNS caused by Brucella have not been investigated at the molecular and cellular levels. Although the role of Brucella lipoproteins in the pathogenesis of neurobrucellosis is currently unknown, bacterial lipoproteins have been implicated in the inflammatory process in other bacterial infections of the CNS. ${ }^{12}$ It has been shown that astrocytes proliferate and undergo apoptosis (typical phenomena in astrogliosis) ${ }^{13,14}$ and produce IL- 6 and TNF- $\alpha$ in response to lipoproteins. Notably, astrogliosis and microglial activation have been also reported in neurobrucellosis, ${ }^{10,11}$ and it remains to be determined whether these facts are triggered by Brucella and its lipoproteins. Because microglial cells are the resident macrophages of the brain $^{15}$ and Brucella is adapted to survive inside macrophages, ${ }^{16,17}$ the activation of microglia during neurobrucellosis, with concomitant secretion of proinflammatory cytokines, is not unexpected. In fact, microglial cells also produce proinflammatory mediators in response to lipoproteins. ${ }^{12}$ Although the cellular source and the bacterial molecules triggering the production of cytokines need to be addressed in neurobrucellosis, a marked elevation of IL-6, IL-8, and macrophage chemoattractant protein (MCP) -1 has recently been demonstrated after cerebral infection with $B$. melitensis. ${ }^{18}$

We contend that inflammation is a key contributor to the pathogenesis of brucellosis. As Brucella invades the CNS, inflammatory responses to this organism may lead to astrogliosis, as well as microglia activation. To verify our premise, we first injected HKBA into the striatum of BALB/c mice to ascertain whether the direct presence of the bacterium in the cerebral tissue could induce astro- gliosis. Once the phenomenon was corroborated, we designed a minimal in vitro model of the interaction of $B$. abortus with cells of the CNS by establishing primary cell cultures of mouse astrocytes and microglia. This model allowed us to elucidate at the single-cell-type level the ability of $B$. abortus to infect and replicate within these cells; the cytokine response to $B$. abortus and to this organism's lipoproteins and LPS; the effector molecules involved; and the effect of these interactions, and thus of innate immunity, on astrogliosis and microglia activation. Here, we present the results of this study.

\section{Materials and Methods}

\section{Animals}

For stereotaxic injections, 6- to 8-week-old female BALB/C mice were used. For the primary cultures of astrocytes and microglia, 2- to 3-day-old BALB/c mice (Instituto de Estudios de la Inmunidad Humoral, Facultad de Farmacia y Bioquímica, Universidad de Buenos Aires, Buenos Aires, Argentina), TNFR p55 $5^{-1-}$ mice $^{19}$ (Universidad de San Luis, Argentina) on a C57BL/6 background, and C57BL/6 wild-type mice (Universidad de San Luis, Argentina) were used. Animals were housed in groups of five animals, under controlled temperature $\left(22^{\circ} \mathrm{C} \pm 2^{\circ} \mathrm{C}\right)$ and artificial light under a 12-hour cycle period. Mice were kept under specific pathogen-free conditions in positive-pressure cabinet (EHRET, Emmendingen, Germany) and provided with sterile food and water ad libitum. All animal procedures were performed according to the rules and standards for the use of laboratory animals of the National Institute of Health, USA. Animal experiments were approved by the Ethical Committees of the Institute Leloir Foundation and the IDEHU Institute.

\section{Bacteria}

B. abortus $\mathbf{S} 2308$ was cultured in tryptose-soy agar supplemented with yeast extract (Merck, Buenos Aires, Argentina). Bacterial numbers on stationary phase cultures were determined by comparing the $\mathrm{OD}$ at $600 \mathrm{~nm}$ with a standard curve as described. ${ }^{3}$ When indicated, Brucella organisms were washed five times for 10 minutes each in sterile PBS, heat-killed by boiling for 20 minutes, aliquoted, and stored at $-70^{\circ} \mathrm{C}$ until used. Absence of $B$. abortus viability subsequent to heat killing was verified by the absence of bacterial grow in tryptose-soy agar.

\section{Lipoproteins and LPS}

B. abortus lipidated outer membrane protein 19 (LOmp19) and unlipidated Omp19 (U-Omp19) were obtained as described. ${ }^{3}$ Both recombinant proteins contained less than 0.25 endotoxin $\mathrm{U} / \mu \mathrm{g}$ of protein as assessed by Limulus Amebocyte Lysates (Associates of Cape Cod). B. abortus S2308 LPS and Escherichia coli 0111k58H2 LPS were provided by I. Moriyon. The synthetic lipohexapeptide (tripalmitoyl-S-glyceryl-Cys-SerLys4-OH $\left[\mathrm{Pam}_{3} \mathrm{Cys}\right]$ ) was purchased from Boehringer Mannheim (Mannheim, Germany). 


\section{Intracranial Stereotaxic Injections}

For stereotaxic injections, animals $(n=5)$ were anesthetized with ketamine chlorhydrate $(150 \mathrm{mg} / \mathrm{kg})$ and xylazine $(15 \mathrm{mg} / \mathrm{kg})$ and then injected in the left striatum with HKBA ( $1 \times 10^{6}$ bacteria), L-Omp19 (500 ng), U-Omp19 (500 ng), or vehicle (PBS) only, using a 50- $\mathrm{mm}$ tipped finely-drawn glass capillary. The stereotaxic coordinates of the left striatum were: bregma $+0.4 \mathrm{~mm}$; lateral +1.8 $\mathrm{mm}$; ventral $-3.0 \mathrm{~mm}$ (Paxinos and Watson, 1986). Striatal injections of $1 \mu \mathrm{l}$ of HKBA, L-Omp19, U-Omp19, or vehicle were infused over four minutes and the capillary tip kept in place for additional two minutes before removal. Mice were sacrificed 24 hours after surgery.

\section{Histology and Immunohistochemistry}

Animals were deeply anesthetized and transcardially perfused with heparinized saline followed by cold $4 \%$ paraformaldehyde (PFA) in $0.1 \mathrm{~mol} / \mathrm{L}$ PBS. After removing the brains, they were placed in the same fixative overnight at $4^{\circ} \mathrm{C}$. Then, the tissues were cryoprotected by immersion in 30\% sucrose, frozen in isopentane, and serially sectioned in a cryostat $(30 \mu \mathrm{m})$ throughout the striatum in the coronal plane. Thirty- $\mu \mathrm{m}$ sections were used either for cresyl violet staining to determine nuclear morphology, or the presence of glial fibrillary acidic protein (GFAP), a marker for astrocyte activation. To detect GFAP-positive cells, free-floating sections were incubated in blocking buffer (1\% donkey serum, $0.1 \%$ Triton in $0.1 \mathrm{~mol} / \mathrm{L} \mathrm{PBS}$ ) for 45 minutes, rinsed in $0.1 \%$ Triton in $0.1 \mathrm{~mol} / \mathrm{L} \mathrm{PBS}$, and incubated overnight with anti-GFAP antibody (DAKO, Dako, Glostrup, Denmark) diluted 1:700 in blocking solution. After 3 washes, the sections were incubated with conjugated donkey-anti-rabbit-cyanine Cy2 antibody (1:250; Jackson Immuno Research Laboratories, Inc, West Grove, PA) for 2 hours, rinsed in 0.1 $\mathrm{mol} / \mathrm{L}$ PBS and mounted in Mowiol (Calbiochem, San Diego, CA). Digital images were collected in a Zeiss LSM 510 laser scanning confocal microscope equipped with a krypton-argon laser.

\section{Cell Cultures}

Primary mixed glial cultures were established from the forebrain of one- to three-day-old BALB/c, wild-type C57BL/6, or TNFRp55 ${ }^{-1-}$ C57BL/6 mice following previously published procedures. ${ }^{20}$ Forebrains were carefully freed of meninges, chopped, dissociated by mechanical disruption with a pipette followed by trypsinization along with shaking for 20 minutes at room temperature. Cells were seeded into polylysine coated flask of $75 \mathrm{~cm}^{2}$ (TPP, Renner,Germany) and grown at $37^{\circ} \mathrm{C}$ in a $95 \%$ air and $5 \%$ $\mathrm{CO}_{2}$ humified atmosphere in Dulbecco's modified Eagle's medium (DMEM) high glucose (Hyclone) containing $10 \%$ heat inactivated FBS (GIBCO BRL, Life Technologies, Grand Island, NY), supplemented with $2 \mathrm{mmol} / \mathrm{L}$ L-glutamine, $1 \mathrm{mmol} / \mathrm{L}$ sodium piruvate, $100 \mathrm{U} / \mathrm{ml}$ penicillin, $100 \mu \mathrm{g} / \mathrm{ml}$ streptomycin and $25 \mu \mathrm{g} / \mathrm{ml}$ fungizone (GIBCO BRL) (complete medium). The medium was re- placed after 24 hours and every 3 days. After approximately 10 days, culture confluence was achieved. Microglia was detached from the mixed glial cultures by shaking for one hour at $180 \mathrm{rpm}$. Cells were recovered from supernatants, centrifuged, and reseeded on 24-well plates (GBO, Greiner Bio One, Maybachstrasse, Germany), at a density of $1 \times 10^{6}$ cells per well in complete medium. After one hour, the medium was replaced to remove nonadherent cells. For the preparation of purified astrocyte cultures, the ten-day mixed glial cultures were shaken for three hours at $180 \mathrm{rpm}$ to eliminate microglia and oligodendrocyte growing on top of astrocytic layer. The remaining adherent cells were detached by trypsinization, and the resulting cell suspension was left at room temperature to allow adherence of microglia on the plastic surface. After 30 minutes, nonadherent cells were collected and centrifuged, then they were resuspended in fresh complete medium in 24-well plates, at a density of $1 \times 10^{6}$ cells per well.

To assess cell purity, detached cells were centrifuged and resuspended in PBS. For detection of microglia, cells were stained with FITC-labeled anti-mouse CD11b (clone M170; BD Pharmingen, San Diego, CA) or isotype control. For detection of oligodendrocytes, cells were stained with FITC-labeled mAb to type-4 $\left(\mathrm{O}_{4}\right.$; Chemicon, Temecula, CA) or isotype control. For detection of astrocytes, cells were fixed with 4\% paraformaldehyde in PBS for 10 minutes at room temperature. Astrocytes were then permeabilized with Triton X-100 (0.1\% in PBS) for 5 minutes at room temperature. Next, cells were blocked with normal goat serum for 30 minutes. Afterward, they were incubated 30 minutes on ice with mouse anti-GFAP mAb (IgG, 1:200; BioGenex Laboratories, San Ramon, CA) or isotype control, followed by FITC-labeled goat $\mathrm{F}\left(\mathrm{ab}^{\prime}\right)_{2}$ anti-mouse IgG (1:50) for 30 minutes on ice. Subsequently, cells were analyzed on a FACSCalibur $®$ flow cytometer (Becton Dickinson Immunocytometry Systems, Mountain View, CA), and 10,000 events were acquired. Data were processed and normalized (shown as \% of maximum) using the FlowJo software (Tree Star).

\section{In Vitro Infection}

Microglia and astrocytes were cultured in 24 well plates at a density of $1 \times 10^{6}$ cells per well in complete medium without the addition of antibiotics. Cells were infected with B. abortus $\mathrm{S} 2308$ at different multiplicities of infection (MOI) for 2 hours in medium containing no antibiotics. Microglia and astrocytes were extensively washed to remove uninternalized bacteria, and infection was maintained for different times in the presence of $100 \mu \mathrm{g} / \mathrm{ml}$ gentamicin and $50 \mu \mathrm{g} / \mathrm{ml}$ streptomycin to kill remaining extracellular bacteria. Cells were washed 3 times with PBS before processing. To monitor Brucella intracellular survival, infected cells were lysed with $0.1 \%(\mathrm{v} / \mathrm{v})$ Triton $X-100$ in $\mathrm{H}_{2} \mathrm{O}$ after PBS washing and serial dilutions of lysates were rapidly plated onto TSB agar plates to enumerate colony forming units (CFUs). 


\section{Stimulation of Cytokines and Chemokines}

Primary astroglial- or microglial-enriched cultures were either infected (as indicated above) or stimulated for 24 hours with $B$. abortus LPS $(1 \mu \mathrm{g} / \mathrm{ml})$, E. coli LPS $(1 \mu \mathrm{g} / \mathrm{ml})$, HKBA $\left(1 \times 10^{7}\right.$ to $1 \times 10^{9}$ bacteria/ml), U-Omp19 (500 $\mathrm{ng} / \mathrm{ml}), \mathrm{L}-O m p 19(10 \mathrm{ng} / \mathrm{ml}$ or $100 \mathrm{ng} / \mathrm{ml}$ or $500 \mathrm{ng} / \mathrm{ml})$, or $\mathrm{Pam}_{3}$ Cys $(50 \mathrm{ng} / \mathrm{ml})$. Secretion of IL-1 $\beta$, IL-6, TNF- $\alpha$, and MCP-1 in the supernatants was quantified by ELISA from $\mathrm{BD}$, and chemokine keratinocyte chemoattractant $(\mathrm{KC})$ (CXCL1) secretion was quantified by ELISA from R\&D Systems Inc. (Mineapolis, MN).

\section{Assessment of Astrocyte Proliferation}

Purified astrocytes were trypsinized and reseeded in complete medium in 96-well flat-bottom plates (GBO), at the density of $2 \times 10^{4}$ cells per well. After 24 hours, the culture medium was replaced with serum-free medium for 24 hours and cells were then treated with HKBA $(1 \times$ $10^{9}$ bacteria/ml), L-Omp19 (500 ng/ml), Pam ${ }_{3}$ Cys (50 $\mathrm{ng} / \mathrm{ml}), \mathrm{mlL}-6(10 \mathrm{ng} / \mathrm{ml})$, or medium with $2 \%$ FBS. Five days later, $1 \mu \mathrm{Ci}$ of $\left[{ }^{3} \mathrm{H}\right]$ thymidin (Amersham Pharmacia Biotech) was added in each well. After 18 hours, cells were harvested on filter mats, dried, and counted using 1600TR liquid scintillation analyzer (Pachard Instruments, Meriden, CT). Each test was performed in triplicate. Results were expressed as the means of total cpm \pm SEM.

Cell proliferation was also assessed by BrdU incorporation and flow cytometry. Briefly, purified astrocytes were obtained as described above and stimulated five days with HKBA $\left(1 \times 10^{9}\right.$ bacteria/ml) or medium with $2 \%$ FBS in presence of $\mathrm{BrdU}(10 \mu \mathrm{mol} / \mathrm{L})$. Cells were then harvested, fixed, permeabilized, and stained with antiBrdU-FITC mAb and analyzed for incorporation of BrdU with a FACSCalibur $®$ flow cytometer. Data were processed using the FlowJo software (Tree Star).

\section{Apoptosis Assays}

To establish apoptosis, primary astrocyte cultures were reseeded at a density of $1 \times 10^{6}$ cells per well in 24-well plates and stimulated for 24 hours with HKBA $\left(1 \times 10^{7}\right.$ to $1 \times 10^{9}$ bacteria/ml), U-Omp19 (500 ng/ml), L-Omp19 (10 ng/ml, 100 ng/ml, 500 ng/ml), Pam ${ }_{3}$ Cys (50 ng/ml), TNF- $\alpha(5 \mathrm{ng} / \mathrm{ml})$, or $4 \%$ PFA. Then, they were recovered by tripsinization and incubated with Annexin V-FITC and Propidium lodide (BD) for 10 minutes on ice. Apoptosis was analyzed on a FACSCalibur ${ }^{\circledR}$ flow cytometer. Data were processed using the FlowJo software (Tree Star). Apoptosis was also assessed quantitatively either by the terminal deoxynucleotidyl transferase dUTP nick-end labeling (TUNEL) assay using the Fluorescein-FragEL DNA Fragmentation Detection Kit (Calbiochem, San Diego, CA), by Hoechst dye 33342 (which visualized nuclear morphology), or by Annexin V-FITC/Propidium lodide (PI) by reseeding astrocytes on permanox chamber slides (Nunc, Roskilde, Denmark), at a density of $2 \times 10^{5}$ cells per well, using the same stimuli mentioned above. Labeled cells were analyzed by fluorescence microscope and counted. The percentage of early plus late apoptotic cells was calculated as the ratio between FITC- + FITC/PIstained cells and the total number of cells per field $\times 100$.

\section{Blocking of Caspase Activity}

Astrocytes $\left(1 \times 10^{6}\right.$ cells per well $)$ seeded in 24-well plates were treated with or without $50 \mu \mathrm{mol} / \mathrm{L}$ of general caspase inhibitor Z-VAD-FMK (R\&D Systems) for 2 hours and then incubated with HKBA $\left(1 \times 10^{9}\right.$ bacteria/ml), L-Omp19 (500 ng/ml), Pam ${ }_{3}$ Cys $(0.1 \mu \mathrm{g} / \mathrm{ml})$, TNF- $\alpha$ (5 $\mathrm{ng} / \mathrm{ml}$ ), Staurosporine (STS, $1 \mu \mathrm{mol} / \mathrm{L}$; Sigma, Steinheim, Germany), or medium. Apoptosis was determined using flow cytometry by Annexin V/PI after 24 hours as described above.

\section{Statistical Analysis}

Statistical analysis was performed with one-way analysis of variance, followed by post hoc Tukey Test. Data were represented as mean \pm SEM.

\section{Results}

\section{The Presence of $\mathrm{B}$. abortus Induces Astrogliosis in the Brain of BALB/c Mice}

Our hypothesis is that $B$. abortus organisms that have access to the brain can cause inflammation and that this inflammatory response may lead to astrogliosis. To corroborate our hypothesis HKBA was injected in the striatum of mice, and 24 hours later animals were sacrificed. After GFAP immunostaining was performed, striatum sections were analyzed by confocal microsopy. An extensive and widespread astrogliosis, defined as GFAP $^{+}$ramified cells, was observed in the whole striatum of all animals injected with HKBA. This activation is considerably more evident close to the injection site (Figure 1A). Also the striatum exhibited a moderate amount of inflammatory infiltrate near the injection site composed of polymorphonuclear neutrophils (Figure 1B) as well as little vasodilatation. Neither GFAP ${ }^{+}$cells nor recruitment of any type of leukocyte were observed in the contralateral hemispheres or in animals injected with PBS (Figure 1A and data not shown). These results indicate that the presence of $B$. abortus within the brain tissue can induce an inflammatory response that leads to astrogliosis and neutrophilic infiltrate.

\section{Immunocytochemical Characterization of Microglia and Astrocyte Cultures}

Because one of the goals of this study was to determine the interactions of $B$. abortus with cells of the innate immunity of the CNS (e.g., astrocytes and microglia) we decided to conduct experiments using microglia and astrocyte cultures from mouse forebrains devoid of any cross-contamination. Culture purity was assessed by surface staining with anti-Mac-1/CD11b (a marker for mac- 
$\mathbf{A}$
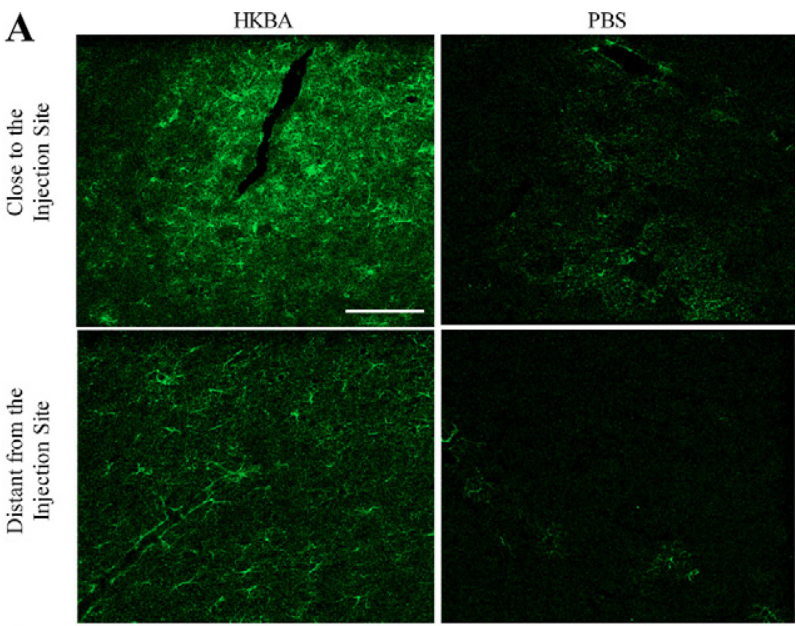

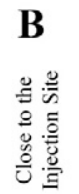
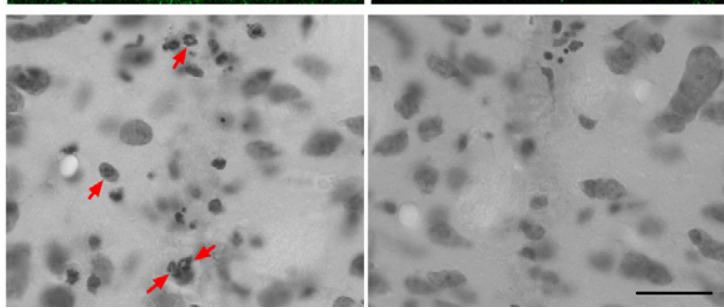

Figure 1. HKBA induces astrogliosis in the striatum of $B A L B / c$ mice. Mice received an intracranial injection of HKBA $\left(1 \times 10^{6}\right.$ bacteria $)$ or vehicle solution (PBS). After 24 hours animals were sacrificed and striatum sections were subjected to immunostaining with anti-GFAP $\mathrm{Ab}(\mathbf{A})$ or with cresyl violet $(\mathbf{B})$, and digital images close to or distant from the injection site were taken by confocal microscopy. Representative images revealed astrogliosis (A) and neutrophil infiltrate (B, arrows) in animals treated with HKBA, but not in PBS-treated ones. Scale bar $=50 \mu \mathrm{m}$.

rophages/microglia), oligodendrocyte type-4 $\left(\mathrm{O}_{4}\right)$, a marker for oligodendrocytes, and by intracellular staining with a mAb specific for the astrocytic intermediate filament protein GFAP. Flow cytometric analysis revealed that microglia and astrocyte cultures contained $90 \%$ Mac $-1^{+}$cells and $95 \%$ GFAP ${ }^{+}$cells, respectively. Mac- $1^{+}$ cells and GFAP $^{+}$cells were virtually absent in astrocyte and microglia cultures, respectively, and no oligodendrocyte contamination in neither cultures was observed (Figure 2A). Phase contrast microscopy corroborated cell morphology (Figure 2B).

\section{B. abortus Infects and Multiplies in Astrocytes and Microglia}

Next, we determined the ability of $B$. abortus to infect astrocytes and microglia. Infection experiments demonstrated that $B$. abortus is internalized by mouse astrocytes and microglia in vitro. Bacteria were also able to multiply efficiently within both cell types. The magnitude of the infection (intracellular CFU) was directly related to the $\mathrm{MOI}$ used. Both infection and intracellular replication were observed even at a $\mathrm{MOI}$ as low as 10 (Figure 3, $\mathrm{A}-\mathrm{C}$ ). The number of bacteria internalized into microglia was higher than that observed for astrocytes after two hours of infection (MOI 100; $1750 \pm 350$ versus $315 \pm$ 163 CFU per well). In both cells lines, after a decline in bacterial numbers at 8 hours, the number of intracellular
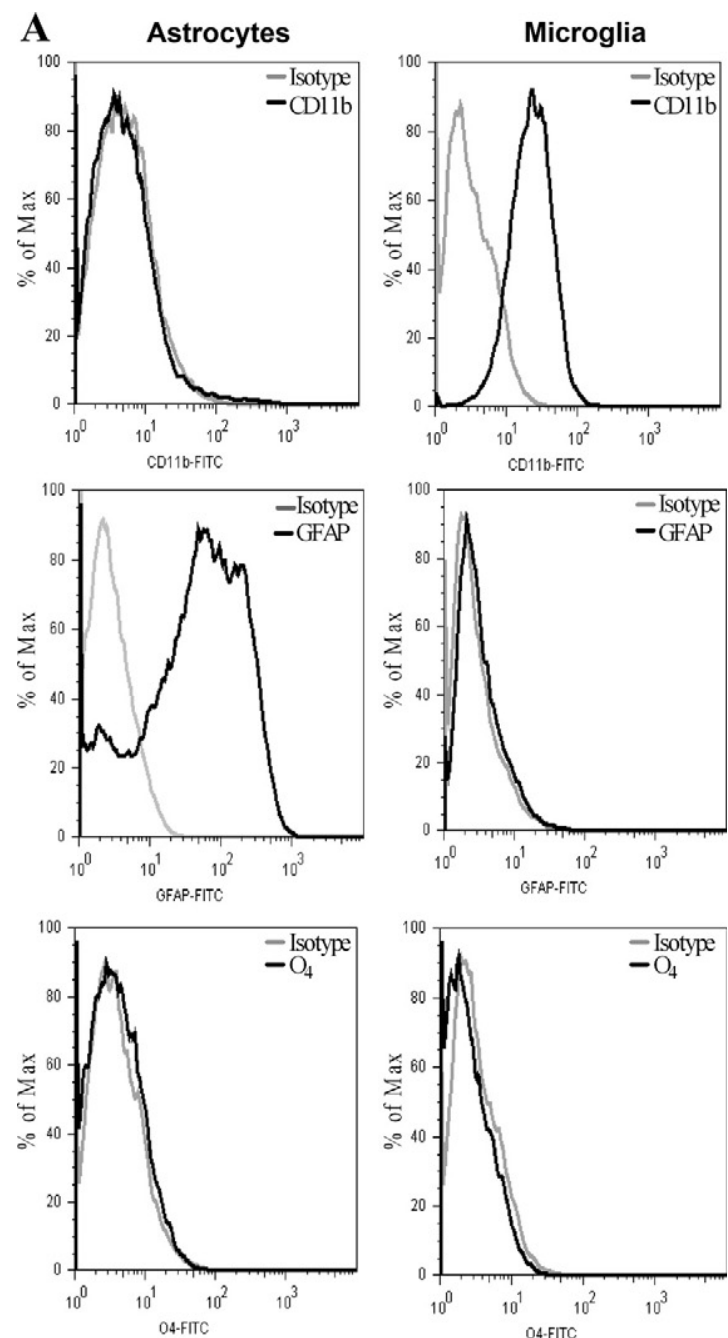

B
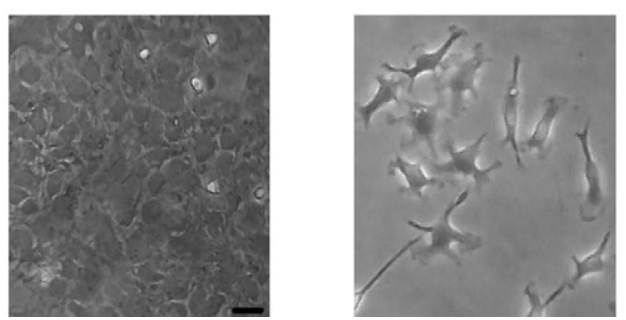

Figure 2. Purity of microglia and astrocyte cultures. Microglia and astrocyte cultures from BALB/c mouse forebrains were prepared as described in Materials and Methods. Cells were stained for surface expression of the macrophage/microglia marker Mac-1/CD11b, for the oligodendrocyte marker $\mathrm{O}_{4}$, or for intracellular expression for the astrocytic marker GFAP Staining with control isotype mAbs is also shown. Cytofluorometric analysis shows that cultures are highly enriched in CD $11 \mathrm{~b} / \mathrm{Mac}-1^{+}$microglia and in $\mathrm{GFAP}^{+}$astrocytes, with no detectable cross-contamination or contamination with oligodendrocytes (A). Phase contrast micrographs of microglia and astrocyte cultures used in this study are also shown (B). Scale bar $=50 \mu \mathrm{m}$.

bacteria increased at 24 hours and continued growing thereafter, nevertheless at any time tested the number of bacteria was higher in microglia than in astrocytes (Figure 3 C). As a control, J774.A1 cells were infected in parallel. The magnitude and the kinetic of infection in microglia were comparable with that of J774.A1 cells, a macrophage cell line that was consistently reported to support Brucella infection and growth (Figure 3C). Infec- 
A

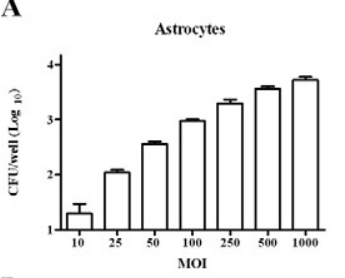

D

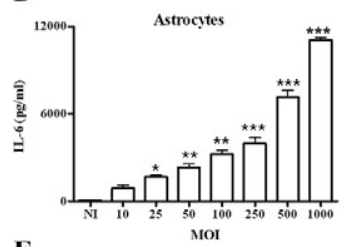

$\mathbf{E}$

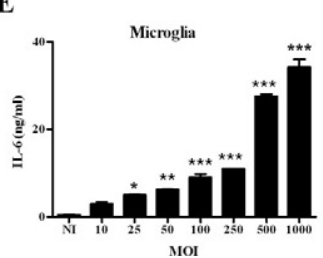

B

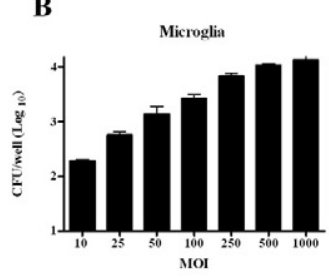

C
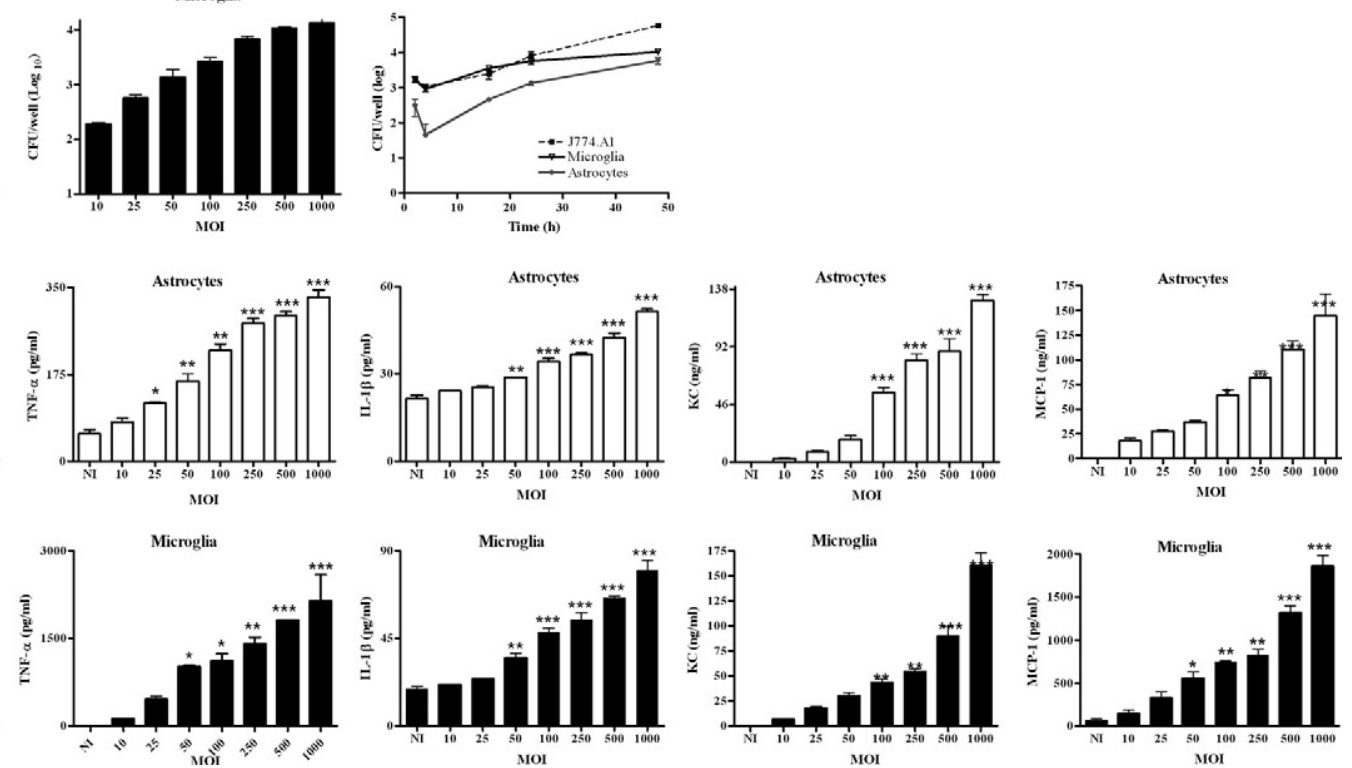

Figure 3. B. abortus infects and multiplies in astrocytes and microglia. Infection with B. abortus was performed at different multiplicity of infection (MOI), and CFU was determined after 24 hours postinfection in astrocytes (A) and microglia (B) cultures. Astrocytes, microglia, and J774.A1 cells were infected with B. abortus (MOI 100), and replication within each cell type was assessed by determination of CFU after 2, 8, 16, 24, or 48 hours (C). ELISA determination of proinflammatory cytokines (IL-6, IL-1 $\beta$, and TNF- $\alpha$ ) and chemokines (KC and MCP-1) in culture supernatants of 24-hour infected astrocytes (D) and microglia (E). Bars and symbols express the mean \pm SEM of duplicates. Data shown are from a representative experiment of three performed. ${ }^{*} P<0.05 ;{ }^{* *} P<0.01 ;{ }^{* * *} P<0.001$ versus N.I. (not infected).

tion resulted in a significant $(P<0.05)$ secretion of IL-6, $\mathrm{IL}-1 \beta$, and TNF- $\alpha$ and the chemokines MCP- 1 and $\mathrm{KC}$ in a MOI-dependent fashion in both types of cells (Figure 3, $\mathrm{D}$ and $\mathrm{E})$.

These results indicate that $B$. abortus can infect and replicate in astrocytes and microglia and, as a result of this infection, proinflammatory mediators are secreted.

\section{Microglia and Astrocytes Produce}

\section{Proinflammatory Cytokines and Chemokines in}

\section{Response to HKBA}

To test whether viable bacteria were necessary to induce a proinflammatory response in astrocytes and microglia, the ability of HKBA to induce the secretion of cytokines and chemokines was examined. E. coli LPS was used as positive control. The production of all cytokines and chemokines was markedly enhanced in culture supernatants of either type of cell that were stimulated with HKBA when compared with the unstimulated cells. Cytokine production was a function of the amount of bacteria present in the culture. A significant $(P<0.05)$ cytokine and chemokine secretion was detected in cultures containing between $1 \times 10^{8}$ and $1 \times 10^{9}$ bacteria/ml (Figure 4); a similar bacterial concentration to that able to elicit the secretion of mediators with live bacteria. These results suggest that this inflammatory response could be induced by a structural component of $B$. abortus.

\section{B. abortus LPS Is Not Involved in the Production of Cytokines and Chemokines Induced by HKBA}

Experiments were then conducted to evaluate the contribution of $B$. abortus LPS to the production of inflammatory mediators elicited in astrocytes and microglia by $B$. abortus. For that purpose, cells were incubated with HKBA as indicated above but in the presence or absence of polymyxin $\mathrm{B}$, a specific inhibitor of the activity of LPS, ${ }^{21}$ and after 24 hours of culture the secretion of IL-6, IL- $1 \beta$, TNF- $\alpha$, MCP-1, and $\mathrm{KC}$ was evaluated by ELISA in culture supernatants. Again, HKBA significantly $(P<0.01)$ induced inflammatory mediators (Figure 5). Cytokine and chemokine secretion was not attributable to $B$. abortus LPS, as the addition of polymyxin $B$ had no effect on HKBA-induced secretion under conditions in which it completely blocked the response to $1000 \mathrm{ng} / \mathrm{ml}$ of E. coli LPS (Figure 5). Moreover, high concentrations of purified $B$. abortus LPS were unable to induce the significant production of any mediator (Figure 5). Taken together, our results indicate that $B$. abortus LPS does not contribute to the secretion of either cytokines or chemokines induced by HKBA, corroborating and extending previous results obtained with other cell types. ${ }^{3-5}$

\section{L-Omp19 Induces Cytokine and Chemokine Secretion in Astrocyte and Microglia}

As B. abortus LPS is not involved in the secretion of inflammatory mediators stimulated in astrocytes and 
Astrocytes
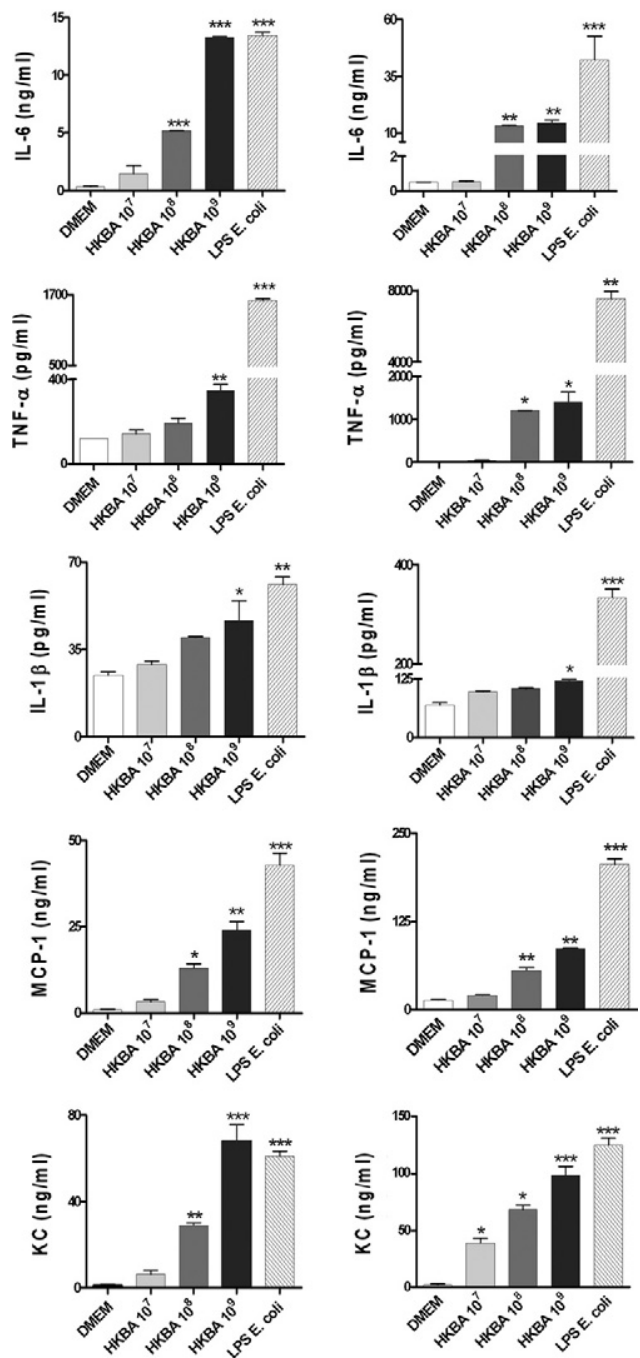

Figure 4. Microglia and astrocytes produce proinflammatory cytokines and chemokines in response to HKBA. Astrocytes and microglia were incubated with DMEM, HKBA $\left(1 \times 10^{7}\right.$ to $1 \times 10^{9}$ bacteria $\left./ \mathrm{ml}\right)$, or $E$ coli $\operatorname{LPS}(1 \mu \mathrm{g} / \mathrm{ml})$. After 24 hours, IL- 6 , IL- $1 \beta$, TNF- $\alpha$, KC, and MCP- 1 were determined in culture supernatants by ELISA. Bars express the mean \pm SEM of duplicates. Data shown are from a representative experiment of five performed. ${ }^{*} P<0.05$ ${ }^{* * *} P<0.01 ;{ }^{* * * *} P<0.001$ versus DMEM.

microglia, and taking into account that we have demonstrated that $B$. abortus lipoproteins were able to induce the secretion of cytokines by other cells of the innate immunity, ${ }^{3-5}$ we hypothesized that Brucella lipoproteins could be the structural components involved in the secretion of cytokines and chemokines. To test this hypothesis, we used lipidated Omp19 (L-Omp19) as a Brucella lipoprotein model. Cells were incubated with L-Omp19, and after 24 hours of culture the secretion of cytokines and chemokines was evaluated in the culture supernatants by ELISA. L-Omp19 induced significant $(P<0.01)$ secretion of IL-6, IL- $1 \beta$, TNF- $\alpha$, MCP- 1 , and $\mathrm{KC}$ in both cell types in a dose-dependent fashion (Figure 6). Cytokine and chemokine secretion induced by Omp19 was dependent on the lipid moiety of the molecule because unlipidated Omp19 (U-Omp19) induced only small or no
Astrocytes
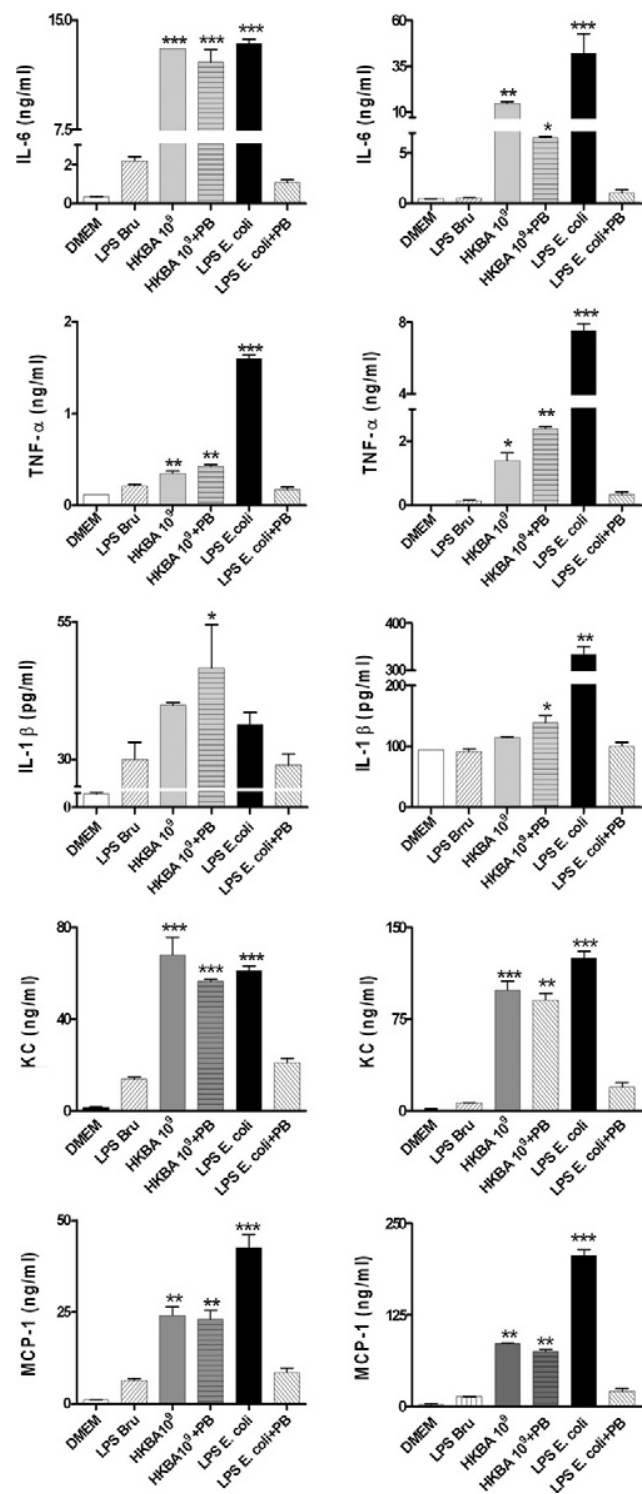

Figure 5. B. abortus LPS does not induce proinflammatory cytokines and chemokines. Astrocytes and microglia were stimulated with DMEM, B. abor tus LPS (LPSBru; $1 \mu \mathrm{g} / \mathrm{ml})$, HKBA $\left(1 \times 10^{9}\right.$ bacteria $\left./ \mathrm{ml}\right)$, HKBA $1 \times 10^{9}$ bacteria $/ \mathrm{ml}+$ polymyxin B (PB); $E$. coli LPS $(1 \mu \mathrm{g} / \mathrm{ml})$ or $E$. coli $\mathrm{LPS}+\mathrm{PB}$. After 24 hours, IL-6, IL- $1 \beta$, TNF- $\alpha, \mathrm{KC}$, and MCP- 1 were quantified in culture supernatants by ELISA. Bars express the mean \pm SEM of duplicates. Data shown are from a representative experiment of five performed. ${ }^{*} P<0.05$ ${ }^{* * *} P<0.01 ;{ }^{* * * *} P<0.001$ versus DMEM

secretion of IL-6, IL- $1 \beta$, TNF- $\alpha, \mathrm{MCP}-1$, and $\mathrm{KC}$. The requirement for lipidation was further supported by the fact that Pam ${ }_{3}$ Cys, a lipohexapeptide with an irrelevant peptide sequence, also induced the production of all mediators (Figure 6). These results indicate that B. abortus lipoproteins induce inflammatory cytokines and chemokines in astrocytes and microglia.

\section{L-Omp19 Induces Astrogliosis in the Brain of BALB/C Mice}

As L-Omp19 was able to induce the activation of astrocytes in vitro, we subsequently tested its ability to induce 
Astrocytes
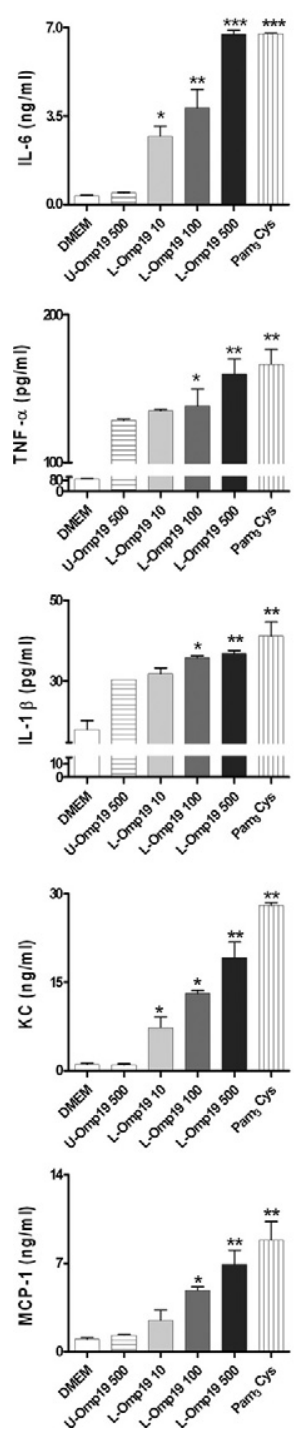

Microglia
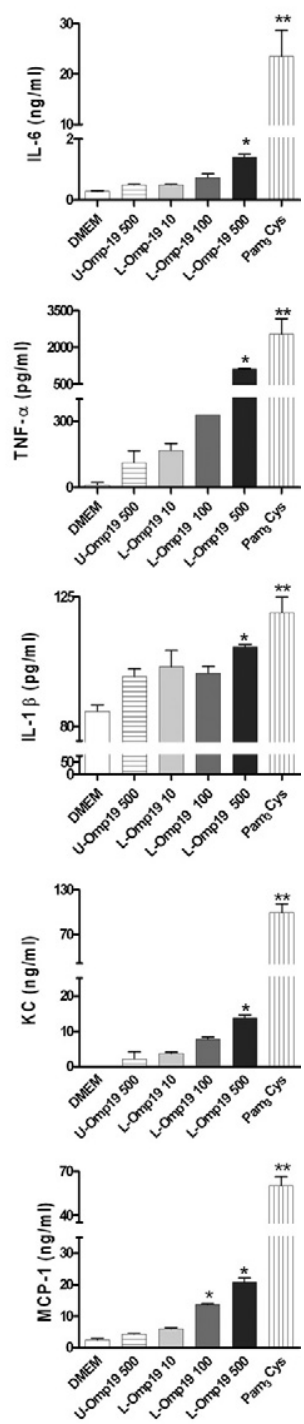

Figure 6. L-Omp19 induces cytokine and chemokine secretion in astrocytes and microglia. Astrocytes and microglia were stimulated with DMEM, UOmp19 $(500 \mathrm{ng} / \mathrm{ml})$, L-Omp19 (10 ng/ml, $100 \mathrm{ng} / \mathrm{ml} \mathrm{or} 500 \mathrm{ng} / \mathrm{ml})$, or Pam $_{3}$ Cys $(50 \mathrm{ng} / \mathrm{ml})$. After 24 hours IL- 6 , IL- $1 \beta$, TNF- $\alpha$, KC, and MCP-1 were quantified in culture supernatants by ELISA. Bars express the mean \pm SEM of duplicates. Data shown are from a representative experiment of five performed. ${ }^{*} P<0.05 ;{ }^{* *} P<0.01 ;{ }^{* * *} P<0.001$ versus DMEM.

astrogliosis in vivo. Therefore, L-Omp19 was injected in the striatum of mice, and 24 hours later animals were sacrificed. U-Omp19 and PBS injection were used as controls. Astrogliosis as determined by increased GFAP staining was evident after the injection of L-Omp19. As with the whole bacterium, $\mathrm{GFAP}^{+}$cells were observed within the striatum and strong ramified $\mathrm{GFAP}^{+}$cells were observed close to the injection site (Figure 7A). The striatum also exhibited a mild amount of inflammatory infiltrate near the injection site composed of neutrophils as well as a little vasodilatation near the injection site (Figure 7B). Neither GFAP $^{+}$cells nor recruitment of any type of leukocyte were observed in the uninjected hemispheres or in animals injected with U-Omp19 or PBS (Figure 7 and data not shown). These results indicate that $B$. abortus

lipoproteins contribute to the astrogliosis induced in vivo by $B$. abortus and that the lipid moiety is needed to induce this phenomenon.

Taken together, our results indicate that $B$. abortus and L-Omp19 induced astrogliosis in vivo. Thus, we next challenged our in vitro model with both stimuli to find out whether they could induce astrocyte proliferation and apoptosis, two key features of astrogliosis. ${ }^{13,14}$

\section{HKBA and L-Omp19 Induce Astrocyte Proliferation in Vitro}

To appraise astrocyte proliferation, astrocytes were left untreated or treated with HKBA, U-Omp19, L-Omp19, or $\mathrm{Pam}_{3} \mathrm{Cys}$, and $\left[{ }^{3} \mathrm{H}\right]$ thymidine incorporation was evaluated. IL-6 was used as a positive control of proliferation. HKBA, L-Omp19, and Pam 3 Cys were able to induce significant $(P<0.01)$ astrocyte proliferation. On the contrary, U-Omp19 was not able to induce proliferation, indicating that the lipid moiety is required to induce this phenomenon. As expected, IL-6 induced astrocyte proliferation (Figure 8B). We also assessed astrocyte proliferation by $\mathrm{BrdU}$ incorporation. Astrocytes were stimulated with HKBA or left with medium alone. BrdU was supplied in the medium, and after culture cells were harvested and processed for flow cytometry. BrdU was incorporated both in the presence and absence of stimulant, as evidenced by the enhanced fluorescence signal of these cultures compared with the control fluorescence level obtained in the absence of BrdU (Figure 8A). HKBAstimulated astrocytes showed two cell populations, one that exhibited a mean fluorescence level almost fourfold the cells exposed to medium alone, and another population whose fluorescence was about one half of that of the unstimulated cells (Figure 8A). These results indicated that $B$. abortus is capable of inducing astrocyte proliferation in vitro. Moreover, the fact that a subpopulation of cells appeared to incorporate BrdU at a rate markedly diminished compared with that of unstimulated cells indicated to us that a concomitant phenomenon was taking place.

\section{B. abortus and L-Omp19 Induce Astrocyte Apoptosis in Vitro}

Because astrocyte apoptosis is known to occur in the context of gliosis, ${ }^{13,14}$ we investigated whether $B$. abortus and L-Omp19 could also induce apoptosis. BALB/C astrocytes were infected, and after 24 hours cells were stained with Annexin V/PI and apoptosis was determined by flow cytometry. B. abortus infection induced astrocyte apoptosis (Figure 9). As B. abortus and other Brucella species are able to inhibit macrophage apoptosis, ${ }^{22,23}$ and taking into account that microglia are the resident macrophages of the brain, ${ }^{15}$ we decided to investigate the effect of $B$. abortus infection in microglia survival as well. Conversely to astrocytes, Brucella infection induced no apoptosis of microglia (Figure 9). 

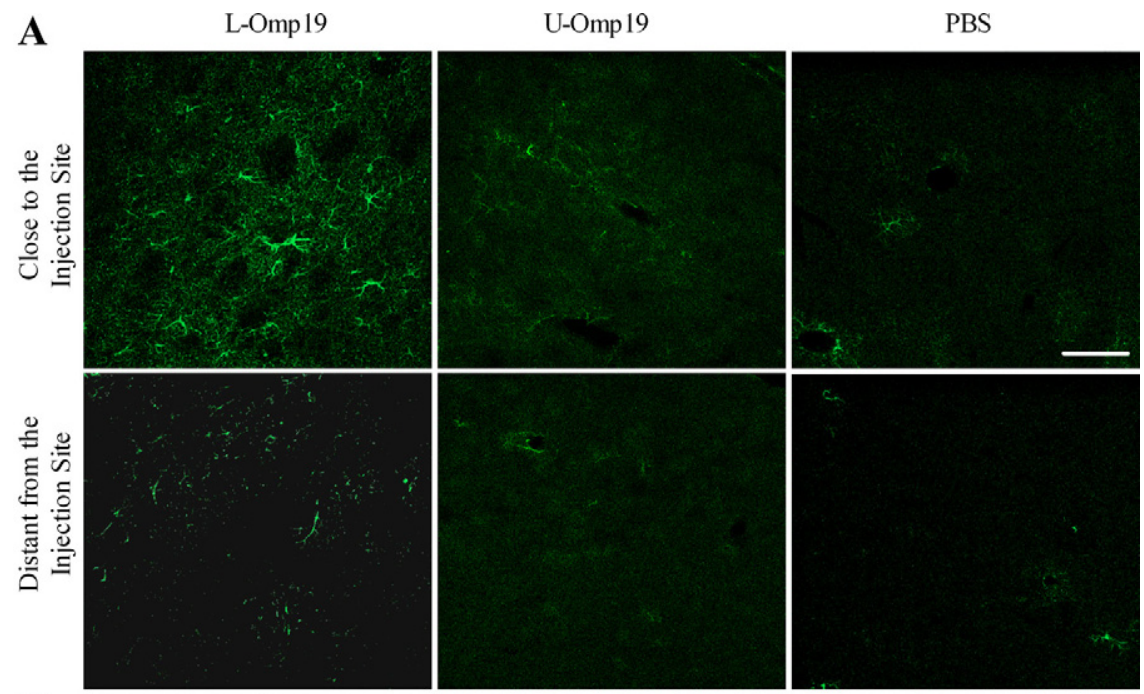

Figure 7. L-Omp19 induces astrogliosis in the striatum of $\mathrm{BALB} / \mathrm{c}$ mice. Mice received an intracranial injection of U-Omp19 $(500 \mathrm{ng} / \mathrm{ml})$, LOmp19 (500 ng/ml), or vehicle solution (PBS). After 24 hours animals were sacrificed and striatum sections were subjected to immunostaining with anti-GFAP Ab (A) or with cresyl violet (B), and digital images close to or distant from the injection site were taken by confocal microscopy. Representative images revealed astrogliosis (A) and neutrophil infiltrate (B, arrows) in animals treated with L-Omp19, but not in UOmp19 (500 ng/ml) or PBS-treated ones. Scale

B
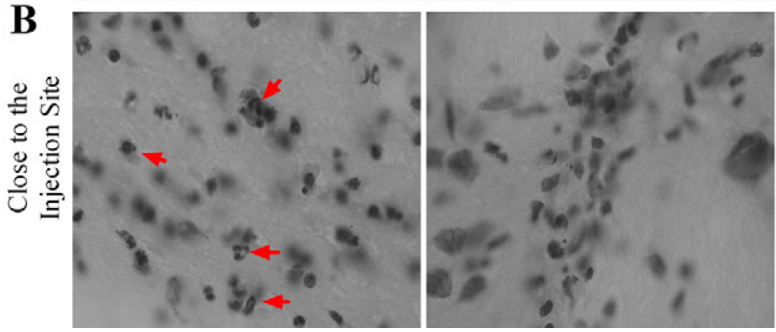

bar $=50 \mu \mathrm{m}$.

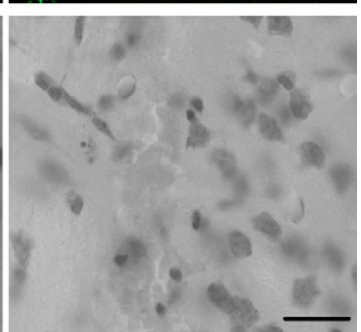

We further analyzed the effect of HKBA and L-Omp19 on astrocyte apoptosis. BALB/c astrocytes were stimulated for 24 hours with medium, different concentrations of HKBA, U-Omp19, L-Omp19, or Pam ${ }_{3}$ Cys, and after staining the cells with Annexin V/PI apoptosis was determined by flow cytometry. TNF- $\alpha$ and PFA were used as positive controls. HKBA and L-Omp19 induced significant $(P<0.05)$ apoptosis in a dose-dependent manner. U-Omp19 did not induce apoptosis, indicating that the lipid moiety of the lipoprotein is directly involved in the phenomenon, a fact confirmed by the ability of $\mathrm{Pam}_{3}$ Cys to reproduce the effect (Figure 10, A and B). Quantitative determinations of apoptosis assessed by AnnexinV/PI, TUNEL assay, or Hoechst dye also determined that HKBA and L-Omp19 significantly $(P<0.05)$ induced apoptosis of astrocytes, confirming and extending the results obtained by flow cytometry (Figure 10, C-E, and data not shown).

Altogether our results indicate that $B$. abortus infection induced astrocyte-but not microglia-apoptosis, and that the lipoproteins of the bacterium are involved in this effect.

\section{HKBA- and L-Omp19-Induced TNF- $\alpha$ Affects Astrocyte Apoptosis}

A key cytokine that can be involved in eliciting astrocyte apoptosis is TNF- $\alpha .{ }^{24}$ To assess the effect of TNF- $\alpha$ on astrocytes, cells from TNFRp55 ${ }^{-1-}$ mice were stimulated for 24 hours with medium, HKBA, L-Omp19, or U-Omp19, and after staining the cells with Annexin V/PI apoptosis was determined by flow cytometry. Astrocytes from
C57BL/6 mice were used as control. Neither HKBA nor L-Omp19 elicited apoptosis of astrocytes from TNFRp55 ${ }^{-1-}$ mice. In contrast, both stimuli were able to induce apoptosis of cells from C57BL/6 mice. U-Omp19 was unable to induce apoptosis in astrocytes from both mouse strains (Figure 11, A and B). As expected, TNF- $\alpha$ did not induce apoptosis of TNFRp55 $5^{-1-}$ astrocytes, but it elicited apoptosis of wild-type astrocytes. Conversely, PFA induced apoptosis in cells from both strains (Figure 11, A and B). The inability of TNFRp55 $5^{-1-}$ astrocytes to become apoptotic after HKBA or L-Omp19 stimulation was corroborated by two independent ways to assess apoptosis such as TUNEL assay or Hoechst dye (Figure 11, C-E). Discrepancies between annexin and tunnel values may be attributable to the fact annexin detects early apoptosis, which it may not progress toward endstage apoptosis but revert to a normal state, ${ }^{25,26}$ overestimating apoptotic cells. Meanwhile, TUNEL assay detects unmistakably DNA fragmentation. Hence, TNF- $\alpha$, acting through TNFR1, determines astrocyte apoptosis, as elicited by $B$. abortus and its lipoproteins.

\section{Caspases Are Involved in Astrocytes Apoptosis Induced by HKBA and L-Omp19}

TNF- $\alpha$ signaling via TNFR1 has been known to induce apoptosis through the coupling of caspase-8 with TNFRSF1A-associated via death domain (TRADD) which, in turn, activates caspase-3. ${ }^{27}$ Therefore, we investigated the role of caspases in the HKBA- and L-Omp19-induced apoptosis. Astrocytes were treated with a general caspase inhibitor (Z-VAD-FMK) and then stimulated with com- 
A

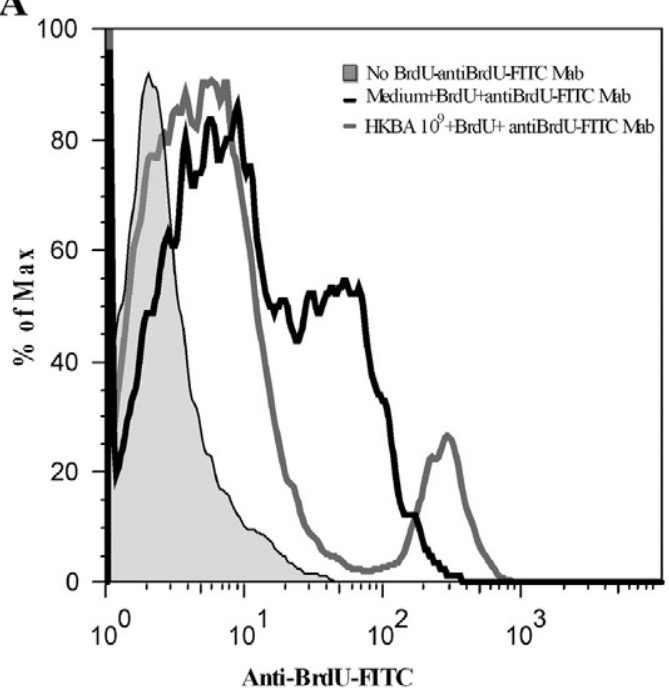

B

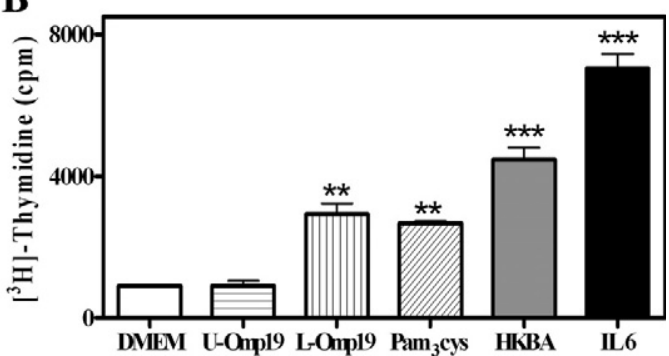

Figure 8. HKBA and L-Omp19 induce astrocyte proliferation. Flow cytometry analysis of BrdU incorporation into BALB/c astrocytes stimulated for 5 days with DMEM or HKBA $\left(1 \times 10^{9}\right.$ bacteria $\left./ \mathrm{ml} ; \mathbf{A}\right)$. Histograms showed are representative of three different experiments. Astrocytes were stimulated with DMEM, HKBA $\left(1 \times 10^{9}\right.$ bacteria/ml), U-Omp19 $(500 \mathrm{ng} / \mathrm{ml})$, L-Omp19 $(500 \mathrm{ng} / \mathrm{ml})$, Pam $_{3}$ Cys $(50 \mathrm{ng} / \mathrm{ml})$, or IL-6 $(10 \mathrm{ng} / \mathrm{ml})$. After five days in culture cell proliferation was estimated by measuring $\left[{ }^{3} \mathrm{H}\right]$ thymidine uptake. Results are expressed in cpm $(\mathbf{B})$. Bars express the mean \pm SEM of triplicates. Data shown are from a representative experiment of five performed. ${ }^{* * *} P<$ $0.01 ;{ }^{* * * *} P<0.001$ versus DMEM.

plete medium, HKBA, or L-Omp19. TNF- $\alpha$ and staurosporine were used as positive controls. Apoptosis was assessed by staining cells with Annexin V/PI and analyzed by flow cytometry. Z-VAD-FMK inhibited the astrocyte apoptosis induced by HKBA and L-Omp19. As ex-
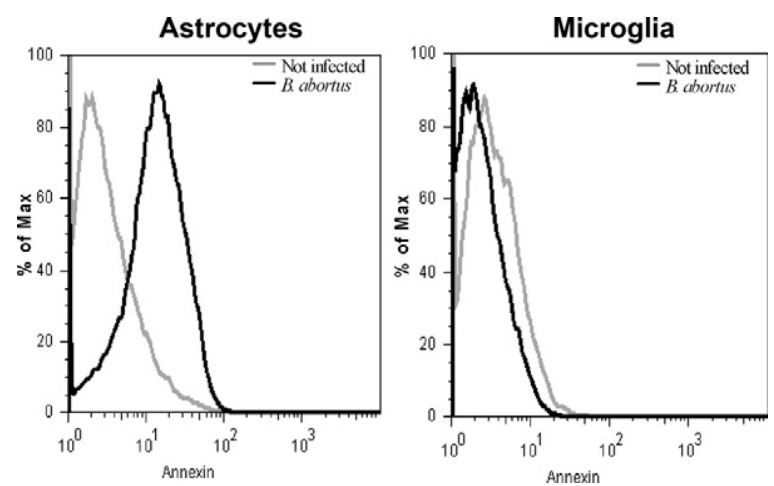

Figure 9. $B$. abortus induces apoptosis in astrocytes but not microglia Astrocytes and microglia were infected with B. abortus at MOI of 100, or they were not infected. After 24 hours, apoptosis was determined using Annexin V/PI staining by flow cytometry. Data shown are from a representative experiment of five performed. pected, TNF- $\alpha$ - and staurosporine-induced apoptosis was also abolished (Figure 12). These results indicate that caspases are involved in astrocytes apoptosis induced by HKBA and L-Omp19. Moreover, they also corroborate that TNF- $\alpha$ signaling via TNFR1 is critical in astrocyte apoptosis as induced by HKBA and L-Omp19.

\section{Discussion}

The precise mechanisms by which brucellae enter the CNS are not known. Because smooth Brucella species have developed several mechanisms to survive intracellularly, especially inside macrophages, phagocyte-facilitated infection (the so-called Trojan-horse mechanism) is a likely mechanism for entry into the CNS. ${ }^{28}$ In addition, Brucella spp. can invade nonprofessional phagocytes, ${ }^{29}$ and so endothelial cell invasion (transcellular traversal) could be another possible route for CNS infection. ${ }^{28}$ Whether the bacterium uses one mechanism or the other, it is clear that once it reaches the CNS it causes an inflammatory pathological response. ${ }^{9}$ The mechanism(s) leading to the signs and symptoms of neurobrucellosis are not known, though it has been proposed that damage to the CNS can be attributed to the direct action of the bacterium or an immunopathological process attributable the effect of proinflammatory cytokines. ${ }^{9,30}$

In this article we present evidence indicating that the direct presence of $B$. abortus induces an inflammatory response leading to astrogliosis in the brain of normal mice. This was achieved using HKBA. It is uncertain whether live bacteria would induce a stronger response or not. However, if HKBA was able to induce astrogliosis we would expect that live $B$. abortus would also produce this feature, at least at a similar level. Mimicking what is documented in patients with neurobrucelosis, ${ }^{31}$ together with the astrogliosis a cellular infiltrate composed of neutrophils was observed, indicating that the microbial insult induced an inflammatory process. This was not observed in animals injected with saline or in areas of the brain in which no bacteria were injected. Thus, there was a causal correlation between the presence of Brucella and the inflammatory process induced in the brain. In view of this, the experimental approach we pursued was aimed to (i) demonstrate, albeit in vitro, the ability of $B$. abortus to infect and replicate within astrocytes and microglia, and to induce an inflammatory response on infection; and (ii) to establish the principle that B. abortus, particularly its lipoproteins, can cause astrogliosis in healthy, naive, astrocytes because of the inflammation elicited. This we believe we have achieved.

To the best of our knowledge, the present study is the first to show that $B$. abortus can infect and multiply within astrocytes and microglia. The bacterium preferentially infects mouse microglia rather than astrocytes. This finding is not particularly surprising, given the considerable literature supporting the tropism of $B$. abortus for macrophages. ${ }^{16,17}$ Likewise other intracellular bacteria that infect cells of the CNS, such as Listeria and Mycobacterium, have a preferential tropism for microglia rather than astrocytes. $^{32,33}$ The fact that $B$. abortus is also able to infect astrocytes adds new evidence to the ability of 
A

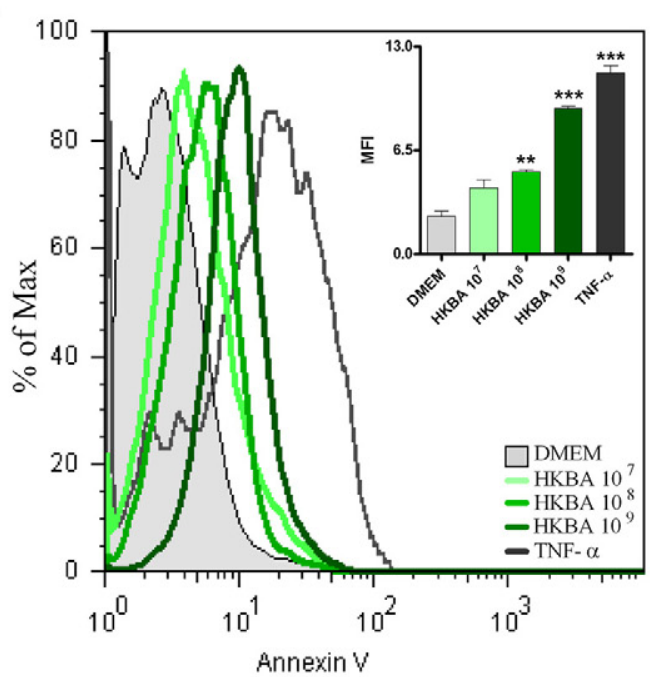

B

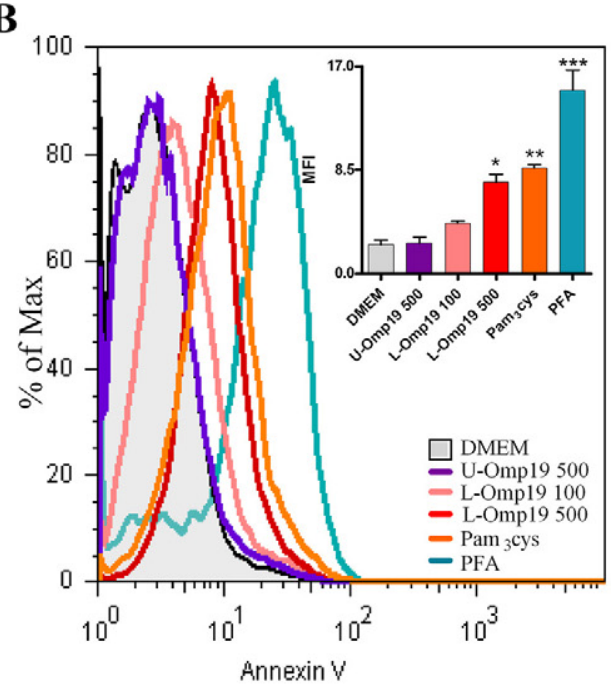

C
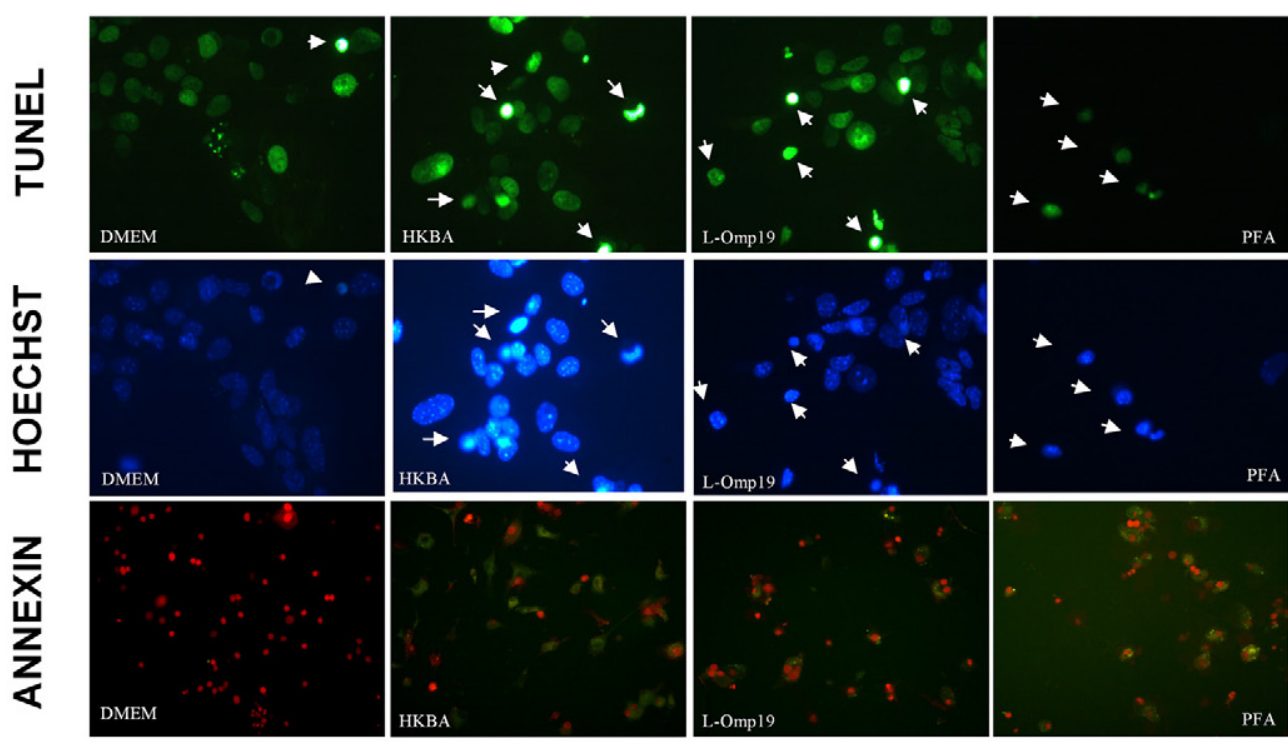

D

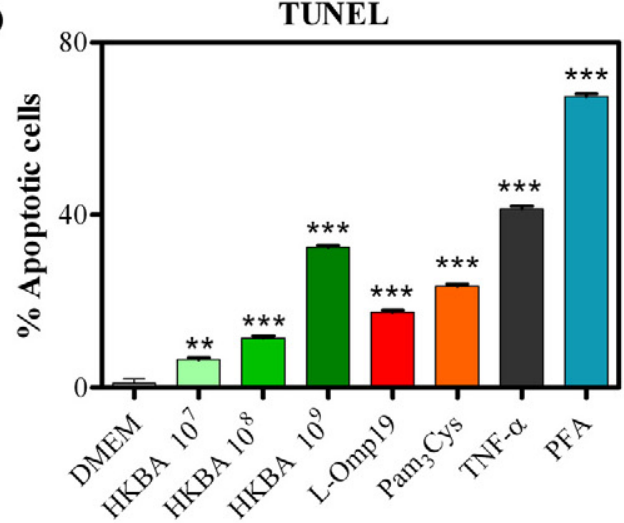

$\mathbf{E}$

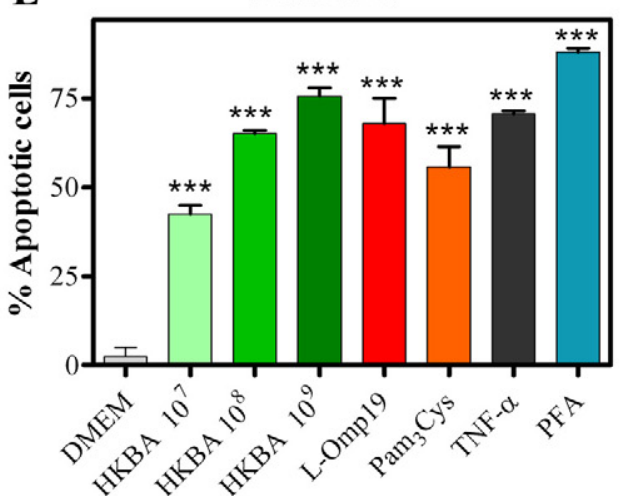

Figure 10. HKBA and L-Omp19 induces astrocyte apoptosis in vitro. BALB/c astrocytes were stimulated with $\mathrm{DMEM}, \mathrm{HKBA}\left(1 \times 10^{7}\right.$ to $1 \times 10^{9}$ bacteria/ml), TNF- $\alpha$ ( $5 \mathrm{ng} / \mathrm{ml})$, U-Omp19 (500 ng/ml), L-Omp19 (100 ng/ml and $500 \mathrm{ng} / \mathrm{ml})$, Pam $_{3}$ Cys ( $\left.50 \mathrm{ng} / \mathrm{ml}\right)$, or $2 \%$ PFA. After 24 hours, apoptosis was determined using Annexin V/PI staining by flow cytometry. Graph bars show the mean fluorescence intensity (MFI) for each stimulus. Bars express the mean \pm SEM of duplicates (A and B). Annexin V/PI, Hoechst dye 33342, and TUNEL assay visualization of apoptosis in astrocytes that were treated for 24 hours with the same stimuli as above. Arrows indicate apoptotic cells $(\mathbf{C})$. Quantification of apoptosis by Annexin V/PI and TUNEL assay. Bars express the mean \pm SEM of duplicates (D and E). Data shown are from a representative experiment of five performed. ${ }^{*} P<0.05 ;{ }^{* *} P<0.01 ;{ }^{* * *} P<0.001$ versus DMEM. 
A

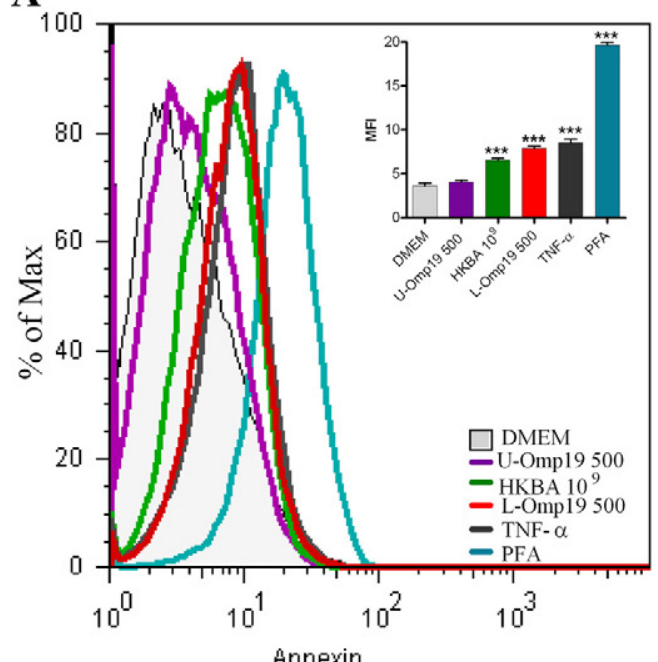

C

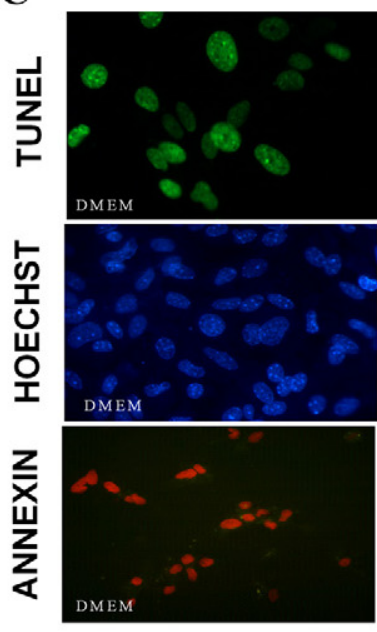

D

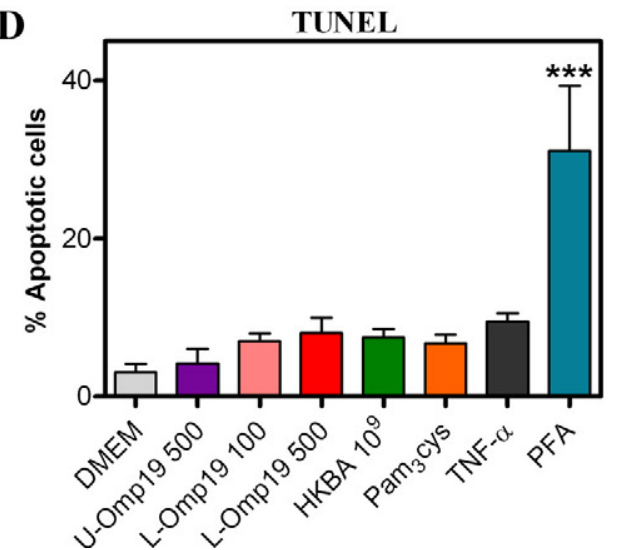

B
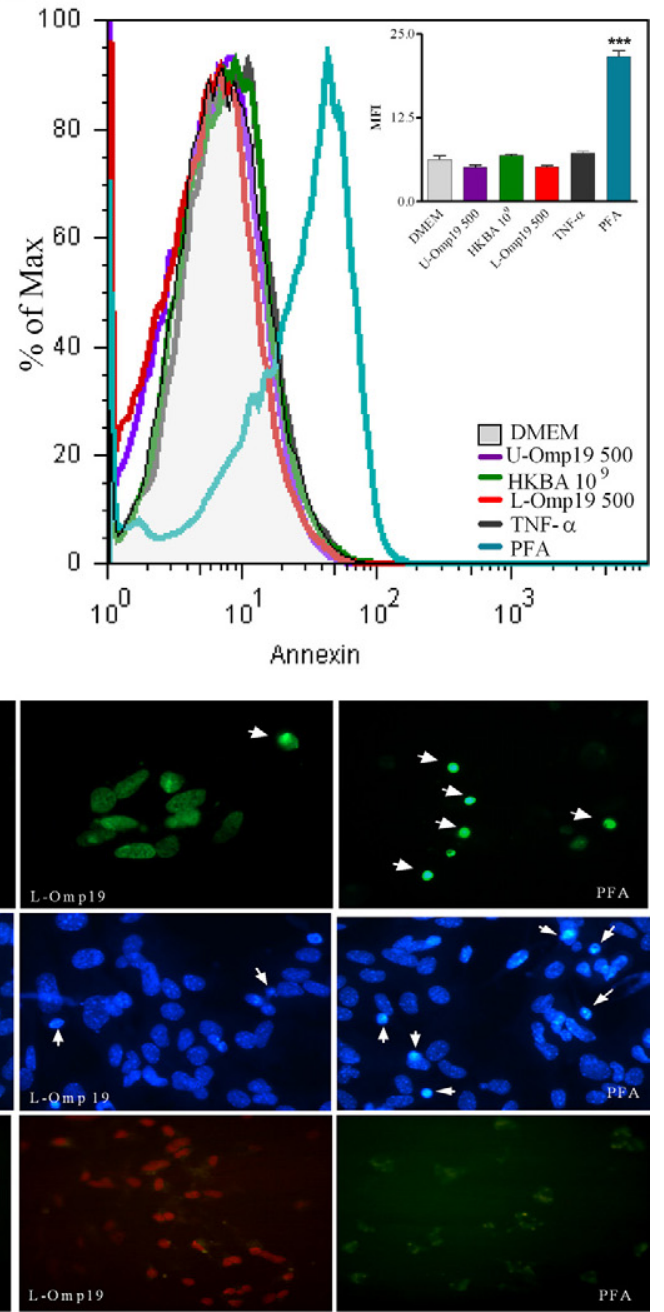

E

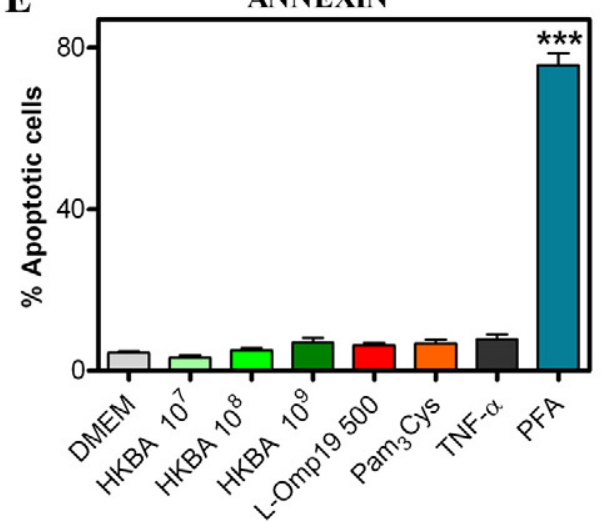

Figure 11. HKBA and L-Omp19 are unable to induce apoptosis in astrocytes from TNFRp $55^{-/-}$mice. Astrocytes from C57BL/ 6 mice $(\mathbf{A})$ or TNFRp $55^{-/-}$mice (B) were stimulated with DMEM, HKBA $\left(1 \times 10^{9}\right.$ bacteria/ml), U-Omp19 (500 ng/ml), L-Omp19 $(500 \mathrm{ng} / \mathrm{ml})$, Pam 3 Cys $(50 \mathrm{ng} / \mathrm{ml})$, TNF- $\alpha(5 \mathrm{ng} / \mathrm{ml})$, or $2 \%$ PFA. After 24 hours, apoptosis was determined using Annexin V/PI staining by flow cytometry. Graph bars show the mean fluorescence intensity (MFI) for each stimulus. Bars express the mean \pm SEM of duplicates. Annexin V/PI, Hoechst dye 33342, and TUNEL assay visualization of apoptosis in astrocytes that were treated for 24 hours with the same stimuli as above. Arrows indicates apoptotic cells (C). Quantification of apoptosis by Annexin V/PI and TUNEL assay. Bars express the mean \pm SEM of duplicates $(\mathbf{D}$ and $\mathbf{E})$. Data shown are from a representative experiment of five performed. ${ }^{*} P<0.05 ;{ }^{* *} P<0.01 ;{ }^{* * * *} P<0.001$ versus DMEM.

this baterium to survive within nonphagocityc cell types, such as osteoblast ${ }^{34}$ and epithelial cells. ${ }^{35}$

There is growing evidence regarding the role of inflammation as a potential pathogenic factor in many diseases of the CNS. Both astrocytes and microglia are principal effectors of immune innate response of the $\mathrm{CNS}^{36-39}$ being activated in pathological conditions such as microbial infections ${ }^{12,32,40}$ and neurodegenerative diseases. ${ }^{41,42}$ In- 

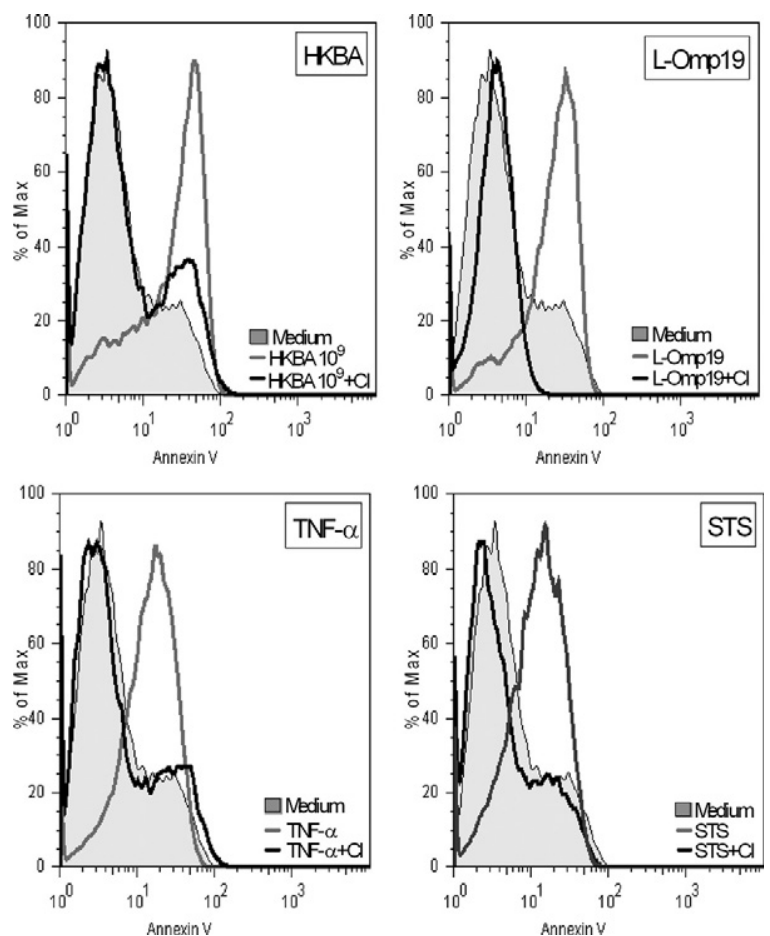

Figure 12. Caspases are involved in HKBA- and L-Omp19-induced apoptosis. BALB/c astrocytes were treated with a general caspase inhibitor (CI; 50 $\mu \mathrm{mol} / \mathrm{L})$, two hours later cells were stimulated with DMEM, HKBA $\left(1 \times 10^{9}\right.$ bacteria/ml), L-Omp19 $(500 \mathrm{ng} / \mathrm{ml})$, Pam $_{3}$ Cys $(50 \mathrm{ng} / \mathrm{ml})$, TNF- $\alpha(5 \mathrm{ng} / \mathrm{ml})$, or staurosporine (STS; $1 \mu \mathrm{mol} / \mathrm{L}$ ). After 24 hours, apoptosis was determined using Annexin V/PI staining by flow cytometry. Data shown are from a representative experiment of five performed.

fection of microglia and astrocytes by $B$. abortus elicits production of a variety of cytokines (TNF- $\alpha, \mathrm{IL}-1 \beta$, and $\mathrm{IL}-6)$ and chemokines (KC and MCP-1). Although these proinflammatory mediators could hypothetically play a role either directly or indirectly in host defense against $B$. abortus, they may also play an important role in the initiation, propagation, and regulation of inflammatory innate immune responses in the brain. Proinflammatory mediators including IL-1 $\beta$, IL-6, TNF- $\alpha$, nitric oxide, reactive oxygen species, and chemokines released by astrocytes and microglia were shown to act contributing to diseases like HIV-encephalitis, ${ }^{43-45}$ Toxoplasma encephalitis, Alzheimer disease, ${ }^{43,45}$ and multiple sclerosis, ${ }^{45}$ among others. In fact, the presence of a neutrophil infiltrate in the brain of mice injected with HKBA could reflect the ability of astrocytes and microglia to secrete $\mathrm{KC}$ one the major chemoattractants responsible for recruiting neutrophils in mice ${ }^{46}$ _on infection/stimulation with $B$. abortus.

The production of inflammatory mediators was not dependent on bacterial viability, because they were also induced by exposure to HKBA, suggesting that they were elicited by a structural bacterial component. We established that the structural element responsible of such response was not $B$. abortus LPS. B. abortus possesses lipoproteins, ${ }^{47}$ and studies conducted in our laboratory have demonstrated that $B$. abortus lipoproteins can elicit inflammatory mediators from many cell types. ${ }^{3-5}$ As other bacterial lipoproteins have the ability to induce inflamma- tory cytokines in cells of the CNS, ${ }^{12}$ we hypothesized that $B$. abortus lipoproteins could be the structural components involved in the observed phenomenon. L-Omp19, a prototypical $B$. abortus lipoprotein, induced the secretion of cytokines (TNF- $\alpha, \mathrm{IL}-1 \beta$, and IL-6) and chemokines (KC and MCP-1) from astrocytes and microglia in a dosedependent fashion. U-Omp19 had no effect, demonstrating that acylation of Omp19 is required for its biological activity. Not only L-Omp19 but also Pam ${ }_{3}$ Cys was able to induce inflammatory mediators. Because all brucellar lipoproteins likely share the $\mathrm{Pam}_{3}$ Cys modification, this entails that any lipoprotein should be able to exert this effect. As the $B$. abortus genome contains no fewer than 80 genes encoding putative lipoproteins, ${ }^{6}$ many of which were shown to be expressed in the outer membrane of the bacterium, ${ }^{47}$ one can envision that the local concentration of Brucella lipoproteins in confined tissue spaces within the brain may be sufficient to exert their biological effects. In this context, we can hypothesize that any surface exposed Brucella lipoprotein may be relevant beyond in vitro assays, and not one lipoprotein but rather a combination of them may contribute to the proinflammatory response elicited by $B$. abortus in astrocytes and microglia.

Astrogliosis is a nonspecific disease manifestation. Astrocytes undergoing gliosis increase in size, divide more rapidly, and actively express GFAP, as well as S-100 protein, amyloid precursor protein, and many receptors. ${ }^{48,49}$ Any injury (infection, autoimmunity, tumor, or stroke) can induce such gliosis, the intensity and duration of which may be limited by astrocyte apoptosis, as reported in HIV encephalitis, ${ }^{50}$ Lyme neuroborreliosis, ${ }^{12}$ Alzheimer disease, ${ }^{51}$ and multiple sclerosis. ${ }^{52}$ Astrogliosis also occurs in neurobrucellosis, ${ }^{10,11}$ and in this work we have corroborated that injection of either the bacterium or a prototypic Brucella liporpotein in the brain of naive mice induce astrogliosis as evidenced by condensation of astrocytic fibers. Our in vitro corroboration that $B$. abortus and its lipoproteins can cause astrogliosis focused on two features of this phenomenon: increase in the rate of cell division and apoptosis. ${ }^{13,14}$

Our results showed that HKBA and L-Omp19 induce astrocyte proliferation. Moreover, assessment of the rate of cell division by BrdU incorporation made it possible to observe a dichotomy in astrocyte behavior in response to HKBA stimulation. About $20 \%$ of the astrocyte population increased its rate of cell division, whereas the remainder of the cells appeared to stop dividing with respect to the rate of division of unstimulated cells. The BrdU incorporation experiments indicated that a subpopulation of astrocytes is capable of increasing its rate of division, and thus exhibit this feature of astrogliosis, in response to $B$. abortus. We assume but did not demonstrate that the non- or slowly dividing subpopulation of astrocytes that was identified in the BrdU incorporation experiment has entered, at least in part, an apoptosis pathway.

The second feature of astrogliosis we chose to explore was apoptosis. B. abortus infection induced astrocyte apoptosis. As with its capacity to induce inflammatory mediators, $B$. abortus-induced apoptosis did not depend on bacterial viability and it was produced, at least, by its 
lipoproteins. Three different determinations (Annexin V/PI, Hoechst dye, and TUNEL) corroborated that HKBA and L-Omp19 induced astrocyte apoptosis. Whether pathogen-induced apoptosis is harmful or beneficial to the host has been a considerable source of debate..$^{53}$ Deregulation of astrocytes generated by the invasion of $B$. abortus might generate a microenvironment in which secretion of proinflammatory mediators could lead to destabilization of glial structure. On the other hand, apoptosis would provide means for the host to down-modulate the inflammatory response and limit the damage caused by proinflammatory bacterial constituents. It seems contradictory that $B$. abortus and its lipoproteins are able to induce astrocyte apoptosis when it has been reported that Brucella species are able to inhibit macrophage apoptosis. ${ }^{22,23}$ Yet, unlike astrocytes, microglia were resistant to Brucella-induced apoptosis. As Brucella are preferentially adapted to infect and replicate in macrophage, ${ }^{16,17}$ and as microglia are the resident macrophages of the brain, their resistance to apoptosis should help to ensure their availability for generation of a chronic infection. The different susceptibilities to apoptosis between astrocytes and microglia are not known, but the fact that apoptosis of astrocytes is mediated by a TLR2 ligand, such as a $B$. abortus lipoprotein L-Omp $19,{ }^{3-5}$ could help to clarify the issue. In their seminal study of TLR2-mediated cell activation, Aliprantis et $\mathrm{al}^{54}$ observed, using transfected HEK293 cells, that bacterial lipoproteins/lipopeptides have proapoptotic properties. In contrast, studies with murine macrophages have failed to confirm that TLR2 signaling is intrinsically apoptogenic. ${ }^{55-58}$ Also it has been reported for other microbial infections a cell-dependent susceptibility to apoptosis, ${ }^{53,59}$ including a differential susceptibility of astrocytes and microglia. ${ }^{60,61}$

TNF- $\alpha$ acts through two distinct cell surface receptors, TNFR1 and TNFR2. TNFR2 is expressed only on hematopoietic and endothelial cells, whereas TNFR1 is expressed on all cell types and initiates the majority of TNF- $\alpha$ biological activities. ${ }^{27}$ Although both TNF- $\alpha$ receptors occur in brain, TNFR1 shows constitutive expression in astrocytes, ${ }^{62}$ whereas TNFR2 is observed only on stimulation. ${ }^{63}$ The major difference between the two receptors is the presence of a death domain on TNFR1, which confers it the ability to induce apoptosis. ${ }^{27} \mathrm{TNF}-\alpha$ signaling via TNFR1 appeared to be the sole determinant of astrocyte apoptosis as induced by B. abortus and its lipoproteins, because apoptosis is completely abolished in astrocytes from TNFRp55 ${ }^{-1-}$. The fact that a pancaspase inhibitor also inhibited Brucella-induced apoptosis underscores the relevance of TNF- $\alpha$ signaling via TNFR1 in this phenomenom, because apoptosis via TNFR1 has been known to involve caspase activation. ${ }^{27}$

The present study of the interaction of $B$. abortus with glial cells has provided potential insights into three key elements of the pathogenesis of CNS brucellosis. First, the bacterium infects microglia and astrocytes with preference for the former cells. Second, infection of both cell types elicits production of a variety of cytokines (TNF- $\alpha$, $\mathrm{IL}-1 \beta$, and IL-6) and chemokines (KC and MCP-1), some of which seem to contribute to CNS damage as they are directly involved in the phenomenon of astrocyte apoptosis elicited by the bacterium. Third, Brucella lipoproteins are main contributors to the inflammatory response elicited by the bacterium. These reasons lead us to postulate that the innate immunity in response to $B$. abortus PAMPs (mainly lipoproteins) would generate inflammatory effects that may eventually lead to glial and neuronal apoptosis. This damage could lead to the neurological deficits observed in neurobrucellosis. ${ }^{8,30}$ Because the physiological net of interactions described in this article does not circumscribe to brucellosis, it is reasonable to assume that the knowledge emerged from this work will be useful to understand other inflammatory disorders in CNS.

\section{Acknowledgments}

We thank Dr. Ignacio Moriyón (University of Navarra, Pamplona, Spain) for E. coli and B. abortus LPS. We also thank Dr. Mario Philipp for the seminal ideas leading to this work.

\section{References}

1. Young EJ: An overview of human brucellosis. Clin Infect Dis 1995, 21:283-289; quiz 290

2. Goldstein J, Hoffman T, Frasch C, Lizzio EF, Beining PR, Hochstein D, Lee YL, Angus RD, Golding B: Lipopolysaccharide (LPS) from Brucella abortus is less toxic than that from Escherichia coli, suggesting the possible use of B. abortus or LPS from B. abortus as a carrier in vaccines. Infect Immun 1992, 60:1385-1389

3. Giambartolomei GH, Zwerdling A, Cassataro J, Bruno L, Fossati CA, Philipp MT: Lipoproteins, not lipopolysaccharide, are the key mediators of the proinflammatory response elicited by heat-killed Brucella abortus. J Immunol 2004, 173:4635-4642

4. Zwerdling A, Delpino MV, Barrionuevo P, Cassataro J, Pasquevich KA, Garcia Samartino C, Fossati CA, Giambartolomei GH: Brucella lipoproteins mimic dendritic cell maturation induced by Brucella abortus. Microbes Infect 2008, 10:1346-1354

5. Barrionuevo P, Cassataro J, Delpino MV, Zwerdling A, Pasquevich KA, Garcia Samartino C, Wallach JC, Fossati CA, Giambartolomei $\mathrm{GH}$ : Brucella abortus inhibits major histocompatibility complex class II expression and antigen processing through interleukin-6 secretion via Toll-like receptor 2. Infect Immun 2008, 76:250-262

6. Halling SM, Peterson-Burch BD, Bricker BJ, Zuerner RL, Qing Z, Li LL, Kapur V, Alt DP, Olsen SC: Completion of the genome sequence of Brucella abortus and comparison to the highly similar genomes of Brucella melitensis and Brucella suis. J Bacteriol 2005, 187: 2715-2726

7. Radolf JD, Arndt LL, Akins DR, Curetty LL, Levi ME, Shen Y, Davis LS Norgard MV: Treponema pallidum and Borrelia burgdorferi lipoproteins and synthetic lipopeptides activate monocytes/macrophages. J Immunol 1995, 154:2866-2877

8. Pappas G, Akritidis N, Bosilkovski M, Tsianos E: Brucellosis. N Engl J Med 2005, 352:2325-2336

9. McLean DR, Russell N, Khan MY: Neurobrucellosis: clinical and therapeutic features. Clin Infect Dis 1992, 15:582-590

10. Sohn AH, Probert WS, Glaser CA, Gupta N, Bollen AW, Wong JD, Grace EM, McDonald WC: Human neurobrucellosis with intracerebral granuloma caused by a marine mammal Brucella spp. Emerg Infect Dis 2003, 9:485-488

11. Seidel G, Pardo CA, Newman-Toker D, Olivi A, Eberhart CG: Neurobrucellosis presenting as leukoencephalopathy: the role of cytotoxic T Iymphocytes. Arch Pathol Lab Med 2003, 127:e374-e377

12. Ramesh G, Alvarez AL, Roberts ED, Dennis VA, Lasater BL, Alvarez X, Philipp MT: Pathogenesis of Lyme neuroborreliosis: borrelia burgdorferi lipoproteins induce both proliferation and apoptosis in rhesus monkey astrocytes. Eur J Immunol 2003, 33:2539-2550 
13. Saas P, Boucraut J, Quiquerez AL, Schnuriger V, Perrin G, DesplatJego S, Bernard D, Walker PR, Dietrich PY: CD95 (Fas/Apo-1) as a receptor governing astrocyte apoptotic or inflammatory responses: a key role in brain inflammation? J Immunol 1999, 162:2326-2333

14. Eddleston M, Mucke L: Molecular profile of reactive astrocytesimplications for their role in neurologic disease. Neuroscience 1993 54:15-36

15. Town T, Nikolic V, Tan J: The microglial "activation" continuum: from innate to adaptive responses. J Neuroinflammation 2005, 2:24

16. Roop RM, 2nd, Bellaire BH, Valderas MW, Cardelli JA: Adaptation of the Brucellae to their intracellular niche. Mol Microbiol 2004 $52: 621-630$

17. Gorvel JP, Moreno E: Brucella intracellular life: from invasion to intracellular replication. Vet Microbiol 2002, 90:281-297

18. Krishnan C, Kaplin Al, Graber JS, Darman JS, Kerr DA: Recurrent transverse myelitis following neurobrucellosis: immunologic features and beneficial response to immunosuppression. J Neurovirol 2005, 11:225-231

19. Pfeffer K, Matsuyama T, Kundig TM, Wakeham A, Kishihara K, Shahinian A, Wiegmann K, Ohashi PS, Kronke M, Mak TW: Mice deficient for the $55 \mathrm{kd}$ tumor necrosis factor receptor are resistant to endotoxic shock, yet succumb to L. monocytogenes infection. Cell 1993, 73:457-467

20. Aloisi F, Ria F, Penna G, Adorini L: Microglia are more efficient than astrocytes in antigen processing and in Th1 but not Th2 cell activation. J Immunol 1998, 160:4671-4680

21. Morrison DC, Jacobs DM: Binding of polymyxin B to the lipid A portion of bacterial lipopolysaccharides. Immunochemistry 1976 13:813-818

22. Gross A, Terraza A, Ouahrani-Bettache S, Liautard JP, Dornand J: In vitro Brucella suis infection prevents the programmed cell death of human monocytic cells. Infect Immun 2000, 68:342-351

23. Eskra L, Mathison A, Splitter G: Microarray analysis of mRNA levels from RAW264.7 macrophages infected with Brucella abortus. Infect Immun 2003, 71:1125-1133

24. Kitsberg D, Formstecher E, Fauquet M, Kubes M, Cordier J, Canton B, Pan G, Rolli M, Glowinski J, Chneiweiss H: Knock-out of the neural death effector domain protein PEA-15 demonstrates that its expression protects astrocytes from TNFalpha-induced apoptosis. J Neurosci 1999, 19:8244-8251

25. Bacso Z, Everson RB, Eliason JF: The DNA of annexin V-binding apoptotic cells is highly fragmented. Cancer Res 2000, 60: 4623-4628

26. Span LF, Pennings AH, Vierwinden G, Boezeman JB, Raymakers RA, de Witte $T$ : The dynamic process of apoptosis analyzed by flow cytometry using Annexin-V/propidium iodide and a modified in situ end labeling technique. Cytometry 2002, 47:24-31

27. Chen G, Goeddel DV: TNF-R1 signaling: a beautiful pathway. Science 2002, 296:1634-1635

28. Kim KS: Mechanisms of microbial traversal of the blood-brain barrier. Nat Rev Microbiol 2008, 6:625-634

29. Pizarro-Cerda J, Meresse S, Parton RG, van der Goot G, Sola-Landa A, Lopez-Goni I, Moreno E, Gorvel JP: Brucella abortus transits through the autophagic pathway and replicates in the endoplasmic reticulum of nonprofessional phagocytes. Infect Immun 1998 66:5711-5724

30. Giambartolomei GH, Wallach JC, Baldi PC: Neurobrucellosis. Encephalitis: Diagnosis and Treatment. Edited by Halperin J. New York, The Egerton Group, 2008, pp 255-272

31. Alba D, Torres E, Molina F, Vazquez JJ: [Neutrophilic pleocytosis in brucella meningitis]. Med Clin (Barc) 1992, 99:478

32. Rock RB, Hu S, Gekker G, Sheng WS, May B, Kapur V, Peterson PK Mycobacterium tuberculosis-induced cytokine and chemokine expression by human microglia and astrocytes: effects of dexamethasone. J Infect Dis 2005, 192:2054-2058

33. Dramsi S, Levi S, Triller A, Cossart P: Entry of Listeria monocytogenes into neurons occurs by cell-to-cell spread: an in vitro study. Infect Immun 1998, 66:4461-4468

34. Delpino MV, Fossati CA, Baldi PC: Proinflammatory response of human osteoblastic cell lines and osteoblast-monocyte interaction upon infection with Brucella spp. Infect Immun 2009, 77:984-995

35. Pizarro-Cerda J, Moreno E, Gorvel JP: Invasion and intracellular trafficking of Brucella abortus in nonphagocytic cells. Microbes Infect 2000, 2:829-835
36. Aloisi F: Immune function of microglia. Glia 2001, 36:165-179

37. Dong Y, Benveniste EN: Immune function of astrocytes. Glia 2001, 36:180-190

38. Farina C, Aloisi F, Meinl E: Astrocytes are active players in cerebral innate immunity. Trends Immunol 2007, 28:138-145

39. Rasley A, Anguita J, Marriott I: Borrelia burgdorferi induces inflammatory mediator production by murine microglia. J Neuroimmunol 2002, 130:22-31

40. Esen N, Tanga FY, DeLeo JA, Kielian T: Toll-like receptor 2 (TLR2) mediates astrocyte activation in response to the Gram-positive bacterium Staphylococcus aureus. J Neurochem 2004, 88:746-758

41. Perry VH: The influence of systemic inflammation on inflammation in the brain: implications for chronic neurodegenerative disease. Brain Behav Immun 2004, 18:407-413

42. Tacconi MT: Neuronal death: is there a role for astrocytes? Neurochem Res 1998, 23:759-765

43. Gonzalez-Scarano F, Baltuch G: Microglia as mediators of inflammatory and degenerative diseases. Annu Rev Neurosci 1999 22:219-240

44. Williams R, Dhillon NK, Hegde ST, Yao H, Peng F, Callen S, Chebloune $\mathrm{Y}$, Davis RL, Buch SJ: Proinflammatory cytokines and HIV-1 synergistically enhance CXCL10 expression in human astrocytes. Glia 2009, 57:734-743

45. Munoz-Fernandez MA, Fresno M: The role of tumour necrosis factor interleukin 6, interferon-gamma and inducible nitric oxide synthase in the development and pathology of the nervous system. Prog Neurobiol 1998, 56:307-340

46. Lee J, Cacalano G, Camerato T, Toy K, Moore MW, Wood WI: Che mokine binding and activities mediated by the mouse IL-8 receptor. J Immunol 1995, 155:2158-2164

47. Tibor A, Decelle B, Letesson JJ: Outer membrane proteins Omp10 Omp16, and Omp19 of Brucella spp are lipoproteins. Infect Immun 1999, 67:4960-4962

48. Ridet JL, Malhotra SK, Privat A, Gage FH: Reactive astrocytes: cellular and molecular cues to biological function. Trends Neurosci 1997, 20:570-577

49. Mucke L, Eddleston M: Astrocytes in infectious and immune-mediated diseases of the central nervous system. FASEB $J 1993$ 7:1226-1232

50. Shi B, De Girolami U, He J, Wang S, Lorenzo A, Busciglio J, Gabuzda D: Apoptosis induced by HIV-1 infection of the central nervous system. J Clin Invest 1996, 98:1979-1990

51. Smale G, Nichols NR, Brady DR, Finch CE, Horton WE, Jr.: Evidence for apoptotic cell death in Alzheimer's disease. Exp Neurol 1995, 133:225-230

52. Dowling P, Shang G, Raval S, Menonna J, Cook S, Husar W: Involvement of the CD95 (APO-1/Fas) receptor/ligand system in multiple sclerosis brain. J Exp Med 1996, 184:1513-1518

53. Byrne GI, Ojcius DM: Chlamydia and apoptosis: life and death decisions of an intracellular pathogen. Nat Rev Microbiol 2004, 2:802-808

54. Aliprantis AO, Yang RB, Mark MR, Suggett S, Devaux B, Radolf JD, Klimpel GR, Godowski P, Zychlinsky A: Cell activation and apoptosis by bacterial lipoproteins through toll-like receptor-2. Science 1999, 285:736-739

55. Haase R, Kirschning CJ, Sing A, Schrottner P, Fukase K, Kusumoto S Wagner $\mathrm{H}$, Heesemann J, Ruckdeschel K: A dominant role of Toll-like receptor 4 in the signaling of apoptosis in bacteria-faced macrophages. J Immunol 2003, 171:4294-4303

56. Hacker G, Kirschnek S, Fischer SF: Apoptosis in infectious disease how bacteria interfere with the apoptotic apparatus. Med Microbio Immunol 2006, 195:11-19

57. Hacker H, Furmann C, Wagner H, Hacker G: Caspase-9/-3 activation and apoptosis are induced in mouse macrophages upon ingestion and digestion of Escherichia coli bacteria. J Immunol 2002, 169:3172-3179

58. Ruckdeschel K, Pfaffinger G, Haase R, Sing A, Weighardt H, Hacker G. Holzmann B, Heesemann J: Signaling of apoptosis through TLRs critically involves toll//L-1 receptor domain-containing adapter inducing IFN-beta, but not MyD88, in bacteria-infected murine macrophages. J Immunol 2004, 173:3320-3328

59. Cruz AR, Moore MW, La Vake CJ, Eggers CH, Salazar JC, Radolf JD: Phagocytosis of Borrelia burgdorferi, the Lyme disease spirochete, potentiates innate immune activation and induces apoptosis in human monocytes. Infect Immun 2008, 76:56-70 
60. Pozner RG, Berria MI, Negrotto S, Schattner M, Gomez RM: Differential astrocyte response to Theiler's murine encephalomyelitis virus infection. Intervirology 2005, 48:279-284

61. Ghadge GD, Ma L, Sato S, Kim J, Roos RP: A protein critical for a Theiler's virus-induced immune system-mediated demyelinating disease has a cell type-specific antiapoptotic effect and a key role in virus persistence. J Virol 1998, 72:8605-8612
62. Dopp JM, Mackenzie-Graham A, Otero GC, Merrill JE: Differential expression, cytokine modulation, and specific functions of type-1 and type-2 tumor necrosis factor receptors in rat glia. J Neuroimmunol 1997, 75:104-112

63. Lung HL, Leung KN, Stadlin A, Ma CM, Tsang D: Induction of tumor necrosis factor receptor type 2 gene expression by tumor necrosis factor-alpha in rat primary astrocytes. Life Sci 2001, 68:2081-2091 